\title{
Experimental and DFT Studies: Novel Structural Modifications Greatly Enhance the Solvent Sensitivity of Live Cell Imaging Dyes
}

\author{
Alexei Toutchkine, ${ }^{\dagger}$ Wen-Ge Han, ${ }^{\ddagger}$ Matthias Ullmann, ${ }^{\S}$ Tiqing Liu,,$"$ Donald Bashford, ${ }^{\perp}$ \\ Louis Noodleman, $*,+$ and Klaus M. Hahn*, \\ Department of Pharmacology and Lineberger Cancer Center, University of North Carolina at Chapel Hill, \\ Chapel Hill, North Carolina 27599, Department of Molecular Biology, TPC-15, The Scripps Research Institute, \\ 10550 North Torrey Pines Road, La Jolla, California 92037, Structural Biology, University of Bayreuth, \\ Universitätsstrasse 30, BGI, 95447 Bayreuth, Germany, University of Maryland Biotechnology Institute, Center \\ for Advanced Research in Biotechnology, 9600 Gudelsky Drive, Rockville, Maryland 20850, and Hartwell \\ Center, St. Jude Children's Research Hospital, 332 North Lauderdale Street, Memphis, Tennessee 38105
}

Received: April 25, 2007; In Final Form: July 30, 2007

\begin{abstract}
Structural modifications of previously reported merocyanine dyes (Toutchkine, A.; Kraynov, V.; Hahn, K. J. Am. Chem. Soc. 2003, 125, 4132-4145) were found to greatly enhance the solvent dependence of their absorbance and fluorescence emission maxima. Density functional theory (DFT) calculations have been performed to understand the differences in optical properties between the new and previously synthesized dyes. Absorption and emission energies were calculated for several new dyes using DFT vertical self-consistent reaction field (VSCRF) methods. Geometries of ground and excited states were optimized with a conductorlike screening model (COSMO) and self-consistent field (SCF) methods. The new dyes have enhanced zwitterionic character in the ground state and much lower polarity in the excited state, as shown by the DFT-VSCRF calculations. Consistently, the position of the absorption bands are strongly blue-shifted in more polar solvent (methanol compared to benzene), as predicted by the DFT spectral calculations. Inclusion of explicit H-bonding solvent molecules within the quantum model further enhances the predicted shifts and is consistent with the observed spectral broadening. Smaller but significant spectral shifts in polar versus nonpolar solvent are predicted and observed for emission bands. The new dyes show large fluorescence quantum yields in polar hydrogen-bonding solvents; qualitatively, the longest bonds along the conjugated chain at the excited $S_{1}$ state minimum are shorter in the more polar solvent, inhibiting photoisomerization. The loss of photostability of the dyes is a consequence of the reaction with and electron transfer to singlet oxygen, starting oxidative dye cleavage. The calculated vertical ionization potentials of three dyes I-SO, AI-SO(4), and AI-BA(4) in benzene and methanol are consistent with their relative photobleaching rates; the charge distributions along the conjugated chains for the three dyes are similarly predictive of higher reaction rates for $\mathrm{AI}-\mathrm{SO}(4)$ and AI-BA(4) than for I-SO. Time-dependent DFT calculations were also performed on AI-BA(4); these were less accurate than the VSCRF method in predicting the absorption energy shift from benzene to methanol.
\end{abstract}

\section{Introduction}

Fluorescent biosensors have enabled visualization of signaling activity in individual, living cells, leading to important insights into spatiotemporal control of signaling pathways. ${ }^{1-4}$ Biosensors of protein conformational change have been produced by covalently labeling proteins with solvent-sensitive fluorescent dyes, ${ }^{5-13}$ such that protein conformational changes affect fluorescence intensity. We have described such dyes (I-SO, I-TBA, S-SO, and S-TBA) ${ }^{14}$ optimized for use in live cell biosensors, with long-wavelength absorbance and emission, high extinction coefficient and quantum yield, water solubility, photostability, and solvent-sensitive fluorescence. A novel biosensor of Cdc42 activation made with one of these dyes showed a 3-fold increase in fluorescence intensity in response to GTP-binding by $\mathrm{Cdc} 42 .{ }^{14}$

* Corresponding authors. E-mail: khahn@med.unc.edu; lou@scripps.edu.

$\dagger$ University of North Carolina at Chapel Hill.

$\doteqdot$ The Scripps Research Institute.

$\S$ University of Bayreuth.

" University of Maryland Biotechnology Institute.

${ }^{\perp}$ St. Jude Children's Research Hospital.
Using dyes that respond to protein activity by changing fluorescence intensity presents difficulties during imaging, since the fluorescence intensity of dyes depends not only on protein conformational changes, but also on variations in cell thickness, uneven illumination, biosensor concentration, and so forth. In the past, such problems have been overcome by normalizing the biosensor signal against other, nonresponsive fluorophores that distribute similarly to the biosensor in cells. ${ }^{15}$ This presents significant problems that are obstacles to quantitative studies of signaling networks; that is, the two fluorophores bleach at different rates and site-specific attachment of two fluorophores to a biosensor can be very challenging. Use of a second fluorophore for normalization is not necessary if the dye undergoes a solvent-dependent shift in its excitation or emission maxima, rather than simply an intensity change. Normalization can then be achieved by monitoring the fluorescence intensity of a single dye at two different wavelengths, rather than the relative intensities of two different dyes (Figure 1).

Our previously reported dyes do possess moderate solventdependent shifts in excitation and/or emission wavelengths, but 


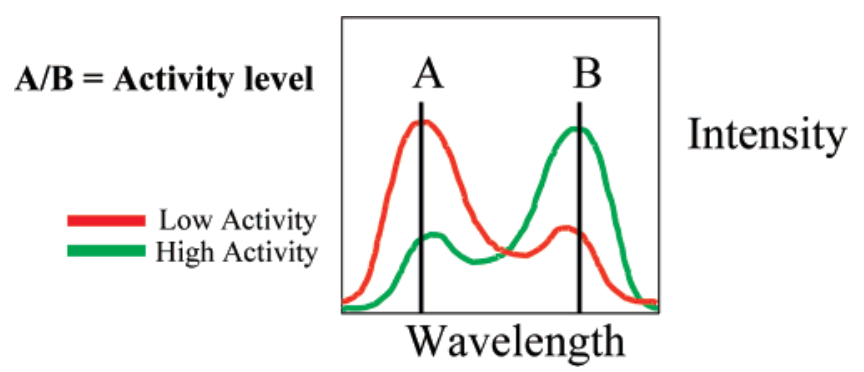

Figure 1. Ratio imaging. When covalently attached to a protein, the dye molecule shifts between two spectra (i.e., spectrum A and spectrum $\mathrm{B})$, as the dye environment is affected by protein conformational changes. Intensity A divided by intensity B reflects the protein environment, regardless of the overall intensity of the fluorescence.

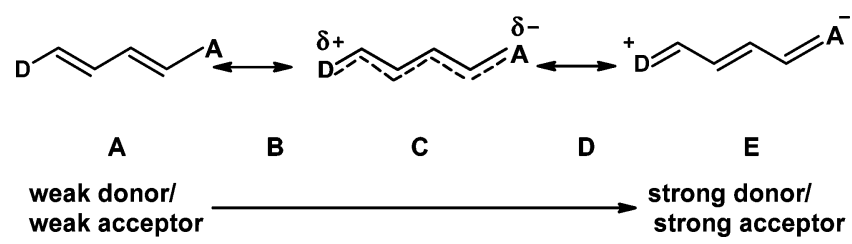

Figure 2. Resonance structures of merocyanine dyes. Depending on the relative electron-donating and -accepting strength of the "donor" (D) and "acceptor" (A) portions of the molecule, the dye can adopt different ground-state structures, ranging from neutral through zwitterionic.

these were insufficient for ratio imaging in cells. The absorption and emission bands present red shifts for I-SO and blue shifts for S-TBA, with increasing solvent polarity. From benzene $\left(\mathrm{C}_{6} \mathrm{H}_{6}\right)$ to methanol $(\mathrm{MeOH})$, the absorption and emission wavelength shifts are 15 and $12 \mathrm{~nm}$ for I-SO and 17 and $11 \mathrm{~nm}$ for S-TBA, respectively. The shifts of the absorption and emission bands of S-SO and I-TBA in other solvents are even smaller. ${ }^{14}$ Here, we describe structural modifications that enhance the solvent-dependent shifts of excitation and emission wavelengths for these merocyanine dyes. As described by Marder and others, ${ }^{16-18}$ merocyanine dyes are insensitive to solvent polarity when their ground states are at the "cyanine limit" (C in Figure 2), with equal contributions from the nonpolar and the zwitterionic resonance structures. Dyes at the cyanine limit are characterized by equal dipole moments in the ground and excited states, so solvents affect both states similarly and there is minimal solvent-dependent change in absorption and emission maxima. We expected that by increasing the strength of the electron donor in the dye structure, the dye's ground-state structure would shift to a more polar form (D in Figure 2), and the dye would have greater solvent-dependent absorption and emission wavelengths. This increase in donor strength was accomplished by a novel introduction of a sixmembered ring into the dye structure. This led to additional aromaticity when the dyes adopted the zwitterionic configuration.

New merocyanine dyes were obtained by adding the sixmembered ring to the electron-donating side of previously reported merocyanine structures (Chart 1). All the dyes were named for the combination of donor and acceptor heterocycles that make up their structure (donors: $\mathrm{I}=$ indolenine, $\mathrm{S}=$ benzothiazole, $\mathrm{O}=$ benzoxazole; acceptors: $\mathrm{SO}=$ benzothiophen-3-one-1,1-dioxide, TBA = thiobarbituric acid). In the new dyes, an "A" is included in the name of the donor ring structure to denote the enhanced aromaticity imparted by the new six-membered ring (i.e., AI-SO and AI-TBA rather than the previously reported I-SO and I-TBA). The number in parentheses indicates the number of methines in the central polymethine chain.
CHART 1: Dye Structures
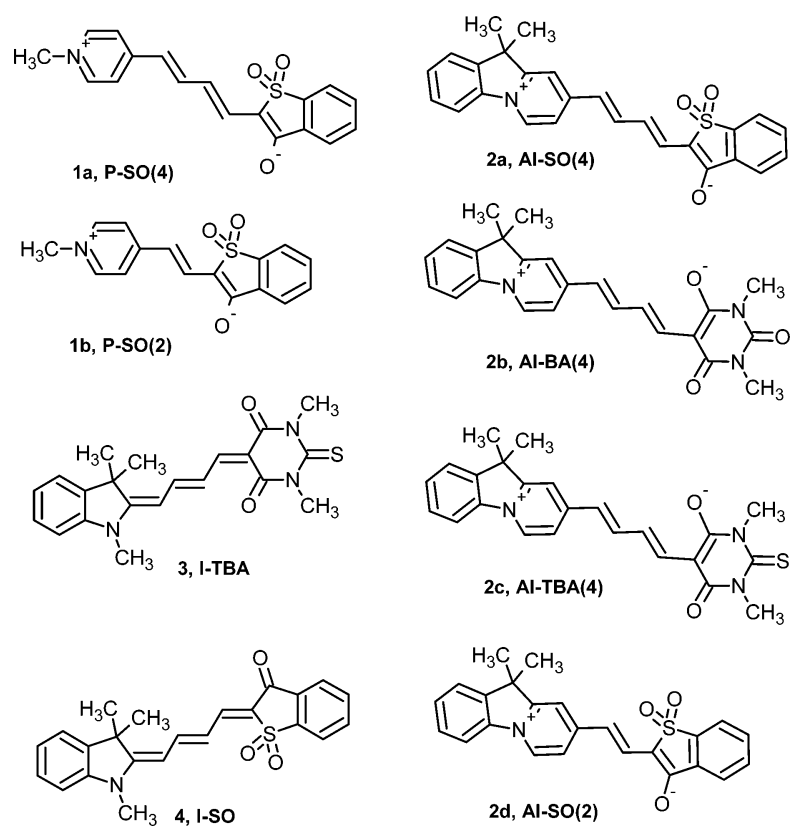

We will show that the absorption band positions of AI-SO(4), AI-TBA(4), and AI-BA(4) are highly solvent-dependent. The shifts of the emission bands of AI-SO(4) and AI-BA(4), though not as significant as those of the absorption bands, are also largely increased. These two dyes are also highly fluorescent in polar solvents such as $\mathrm{MeOH}$.

In this article, we describe density functional theory (DFT) studies to examine how modifications of the donor structure affect dye solvent sensitivity. Several photophysical properties of these dyes were correctly predicted and analyzed using the DFT vertical self-consistent reaction field (VSCRF) ${ }^{19,20}$ method for calculating the spectra, plus a conductor-like screening solvation model (COSMO) $)^{21-24}$ for optimizing geometries. This work points to structural features that can be incorporated to enhance the solvent sensitivity of a broad range of merocyanine dyes.

\section{Methods}

2.1. Synthesis. The synthesis of the new dyes $\mathbf{1 a}, \mathbf{b}$ and $\mathbf{2 a}-\mathbf{d}$ was accomplished according to Scheme 1. A detailed description of new synthetic procedures for this family of dyes will be published elsewhere. The synthesis of dyes $\mathbf{3}$ and 4 (I-TBA and I-SO) was described previously. ${ }^{14}$

2.2. Computation. All quantum mechanical DFT calculations were performed using the Amsterdam Density Functional (ADF, version 2000) package. ${ }^{25}$ The parametrization of Vosko, Wilk, and Nusair (VWN) ${ }^{26}$ was used for the local density approximation term, and the corrections of Becke (1988) (B) ${ }^{27}$ and Perdew (1986) $(\mathrm{P})^{28,29}$ were used for the nonlocal exchange and correlation terms. The molecular orbitals were expanded in an uncontracted triple- $\zeta$ Slater-type orbital basis set, along with a single set of polarization functions. The inner core shells of $\mathrm{C}(1 \mathrm{~s}), \mathrm{N}(1 \mathrm{~s}), \mathrm{O}(1 \mathrm{~s})$, and $\mathrm{S}(1 \mathrm{~s}, 2 \mathrm{p})$ were treated by the frozen core approximation. The accuracy parameter (accint) for the numerical integration grid was set to 4.0.

We recently established a density functional VSCRF solvation model for predicting vertical excitation energies and the solvatochromic shift of solvent-sensitive dyes in different solutions. ${ }^{19}$ We have successfully applied this method to predict the UV absorption and emission blue shifts of Brooker's 
SCHEME 1: Synthesis of Dyes 1a,b and $2 \mathrm{a}-\mathrm{d}^{a}$
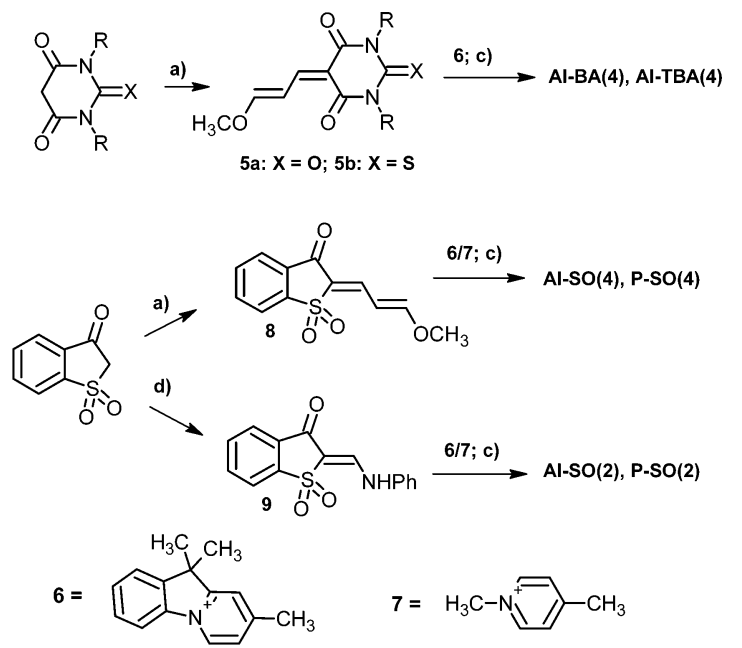

${ }^{a}$ Conditions: (a) Malonoaldehyde bis(dimethyl acetal), $\mathrm{CF}_{3} \mathrm{COOH}$, $95^{\circ} \mathrm{C}, 2$ h. (b) Malonoaldehyde bis(dimethyl acetal), $\mathrm{CF}_{3} \mathrm{COOH}, 130$ ${ }^{\circ} \mathrm{C}, 2$ h. (c) $N$-Methylpiperidine, $\mathrm{MeOH}$, reflux 30-60 min. (d) Diphenylformamidine, AcOH- $\mathrm{Ac}_{2} \mathrm{O}, 120^{\circ} \mathrm{C}, 2 \mathrm{~h}$.

merocyanine from $\mathrm{CHCl}_{3}$ to $\mathrm{H}_{2} \mathrm{O}$ solutions with increasing solvent polarity, and the solvatochromic shifts of both the absorption and emission processes for S-TBA merocyanine, ${ }^{30}$ Abdel-Halim's merocyanine, ${ }^{31}$ the rigidified aminocoumarin C153, ${ }^{32-34}$ and Nile red $^{35,36}$ in different solutions. ${ }^{19,20}$ This VSCRF model was developed in the framework of DFT with $\triangle$ SCF methodology. Its implementation is based on our original self-consistent reaction field (SCRF) development, ${ }^{37-39}$ where the solute molecule is computed by DFT method in the presence of a solvent reaction field. The reaction field is evaluated from a finite-difference solution to the Poisson-Boltzmann equation and self-consistency between the reaction field and the electronic structure of the solute is achieved by iteration. The SCRF calculation applied to a solute geometry allows the electronic structure relaxation in both the solute and the solvent and, implicitly, the orientational (geometry) relaxation of the solvent. Once the SCRF calculation on the ground state $\left(S_{0}\right)$ (or the first excited singlet state, $S_{1}$ ) is achieved, the VSCRF procedure on the excited state (or the ground state) allows only the electronic structure reorganization for both the solute and solvent, and the vertical excitation (or emission) in solution is then obtained. The detailed principles and procedures for VSCRF calculations in both absorption and emission processes, including the $\triangle \mathrm{SCF}$ spin-decontamination methodology for the first excited singlet state $\left(S_{1}\right)$ energy, can be found in refs 19 and 20.

The solute geometries in $\mathrm{C}_{6} \mathrm{H}_{6}$ and $\mathrm{MeOH}$ were optimized using the COSMO model in ADF. ${ }^{21-24}$ The COSMO model is a dielectric solvent continuum model in which the solute molecule is embedded in a molecular-shaped cavity surrounded by a dielectric medium with given dielectric constant $\epsilon$. In our current COSMO and SCRF calculations, we used $\epsilon=2.3$ for $\mathrm{C}_{6} \mathrm{H}_{6}$ and $\epsilon=32.6$ for $\mathrm{MeOH}$. The optical dielectric constant $\epsilon_{\mathrm{op}}=2$ was used in VSCRF calculations. The dielectric boundary between the interior (with $\epsilon=1$ ) and the exterior of the solute region in all COSMO, SCRF, and VSCRF calculations was defined by the contact surface of rolling a probe sphere (with radius $r=3.5$ and $2.5 \AA$ for $\mathrm{C}_{6} \mathrm{H}_{6}$ and $\mathrm{MeOH}$, respectively) over the solute. The van der Waals radii for atoms $\mathrm{C}, \mathrm{O}, \mathrm{N}, \mathrm{S}$, and $\mathrm{H}$ were taken as $1.7,1.4,1.55,1.8$, and $1.2 \AA$, respectively. Cavitation and dispersion corrections were not included, but these should be similar for the ground and vertical excited states. For the absorption process, the $S_{0}$ state of the
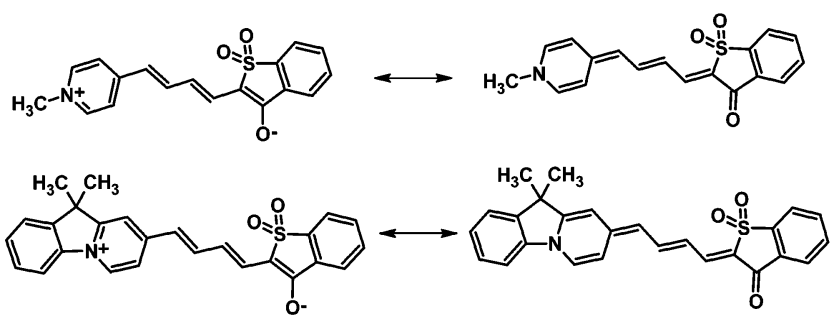

dipolar, aromatic

neutral, non-aromatic

Figure 3. Ground state of merocyanine dyes with and without aromatic stabilization of a charged donor ring. The incorporation of an additional six-membered ring strongly favors the charged zwitterionic resonance form.

solute was relaxed in different solvent dielectrics $\left(\mathrm{C}_{6} \mathrm{H}_{6}\right.$ and $\mathrm{MeOH})$. Correspondingly, for the emission process, the geometry optimizations were performed on the $S_{1}$ state. An electron was promoted from $\beta$-HOMO to $\beta$-LUMO during the $S_{1}$ state geometry optimizations. Our SCRF/VSCRF calculations were then performed on the COSMO-optimized geometries.

As in our earlier work, ${ }^{19,20}$ the absorption and emission energies were calculated as vertical excitations in the framework of the Franck-Condon principle ${ }^{19,20,40}$ without explicit inclusion of vibrational effects. We neglect zero-point energies, vibrational thermal energies, and vibrational entropy contributions to the free energy in the ground state and vertical excited state for absorption (and similarly for emission). These effects will partially subtract out in the excitation energies which are energy differences. Furthermore, in the vertical excited state (for absorption), complex issues arise about proper vibrational ensembles, time scales, and partial thermal equilibrium, involving also the solvent bath. While there can be some overall effect of these corrections on the absolute calculated excitation energies, the effects on solvent-dependent shifts are probably small. In contrast to vibrational effects, both COSMO and SCRF/VSCRF calculations include the electronic polarization of the dye by the solvent; the latter effect is important, as will be shown by the differences in dipole moment in different solvents.

\section{Results and Discussion}

Experimentally, we compared merocyanines with more zwitterionic ground states (dyes $\mathbf{1 a}, \mathbf{b}$ and $\mathbf{2 a}-\mathbf{d}$ in Chart 1) to merocyanines that should be closer to the cyanine limit (dyes $\mathbf{3}$ and 4 in Chart 1). The more zwitterionic merocyanines were made by incorporating a strong donor ring, either 4-pyridine or $10 H$-pyrido[1,2- $a$ ]indolenine, in the structures. These rings were predicted to stabilize the polar, zwitterionic form of the dyes in the ground state, because of the enhanced aromaticity of the zwitterionic resonance form (Figure 3).

From a theoretical perspective, we have compared DFT calculations, evaluating geometries, excitation and emission energies, H-bonding effects, molecular orbital and bonding characters, dipole moments, and the atomic charge distributions for dyes I-SO (4), I-TBA (3), AI-SO(4) (2a), AI-BA(4) (2b), and AI-TBA(4) (2c) to examine why the solvent dependencies in absorption and emission, the fluorescence quantum yield, and photobleaching properties change from I-SO to AI-SO(4) and from I-TBA to AI-BA(4) and AI-TBA(4). These properties are also compared in nonpolar $\mathrm{C}_{6} \mathrm{H}_{6}$ and in polar $\mathrm{MeOH}$ solvents.

3.1. Isomers of the Dye Molecules. Using the COSMO model in ADF2000, we geometry-optimized all the possible isomer conformations for the dyes $\mathbf{2 a}-\mathbf{c}, \mathbf{3}$, and $\mathbf{4}$ in $\mathrm{C}_{6} \mathrm{H}_{6}(\epsilon$ 
TABLE 1: Calculated Relative Energies (kcal mol ${ }^{-1}$ ) of the Different Isomers of Each Dye Molecule in $\mathrm{C}_{6} \mathbf{H}_{6}$ and $\mathrm{MeOH}^{a}$

\begin{tabular}{llcccc}
\hline & & \multicolumn{4}{c}{ isomers } \\
\cline { 3 - 6 } \multicolumn{1}{c}{ dye } & solvent & $\begin{array}{c}1 \text { trans } 4 \\
9 \text { trans } 5\end{array}$ & $\begin{array}{c}1 \text { cis } 4 \\
\text { 9 trans } 5\end{array}$ & $\begin{array}{c}1 \text { trans } 4 \\
9 \text { cis } 5\end{array}$ & $\begin{array}{c}1 \text { cis } 4 \\
9 \text { cis } 5\end{array}$ \\
\hline I-TBA & $\mathrm{C}_{6} \mathrm{H}_{6}$ & 0.00 & 2.42 & & \\
& $\mathrm{MeOH}$ & 0.00 & 2.45 & & \\
AI-TBA(4) & $\mathrm{C}_{6} \mathrm{H}_{6}$ & 0.00 & 0.38 & & \\
& $\mathrm{MeOH}$ & 0.00 & 0.56 & & \\
AI-BA(4) & $\mathrm{C}_{6} \mathrm{H}_{6}$ & 0.00 & 1.72 & & \\
& $\mathrm{MeOH}$ & 0.00 & 0.63 & 0.00 & 1.66 \\
I-SO & $\mathrm{C}_{6} \mathrm{H}_{6}$ & 0.05 & 0.66 & 0.00 & 1.95 \\
& $\mathrm{MeOH}$ & 0.00 & 0.80 & 0.43 & 1.08 \\
AI-SO(4) & $\mathrm{C}_{6} \mathrm{H}_{6}$ & 0.56 & 0.00 & 1.72 & 2.03 \\
& $\mathrm{MeOH}$ & 0.75 & 0.00 & 2.04 &
\end{tabular}

${ }^{a}$ See structures in Chart 2 for the atomic labeling. Here, for instance, " 1 trans 4, 9 trans 5" means that "atom 1 is trans to atom 4, and atom 9 is trans to atom 5".

CHART 2: Geometry-Optimized Structures and Numbering Convention for the Merocyanine Dyes
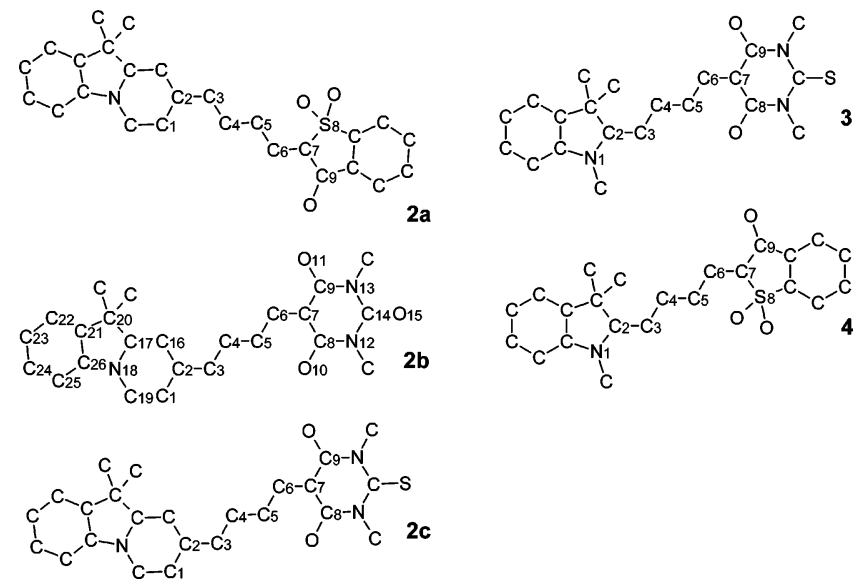

$=2.3)$ and in $\mathrm{MeOH}(\epsilon=32.6)$. NMR spectra of these dyes were consistent with an all-trans configuration of the central polymethine bridge. Our calculations show that the relative energies of the different isomers for each dye are very small (overall $<2.5 \mathrm{kcal} \mathrm{mol}^{-1}$; Table 1). From an energetic point of view, different isomers for a certain dye may coexist in the solvents. In reality, which isomers are measured in the experiment highly depends also on the synthetic procedure. Here, we simply chose the lowest energy structures of each dye in $\mathrm{MeOH}$ for our further calculations in both $\mathrm{C}_{6} \mathrm{H}_{6}$ and $\mathrm{MeOH}$. These structures with numbering conventions are shown in Chart 2. In fact, our tests using SCRF/VSCRF calculations show very similar electronic structures and absorption energies (with differences normally less than $0.02 \mathrm{eV}$ ) for different isomers of a given dye in a given solvent.

3.2. Absorption Spectra. The experimental absorption data for the dyes are summarized in Table 2 and Figure 4. With decreasing solvent polarity, the absorption maximum of dyes $\mathbf{1 a}, \mathbf{b}$, and $\mathbf{2 a}-\mathbf{d}$ shifted to longer wavelengths, and the intensity of the transition increased (Table 2, Figure 4). Such a hypsochromic (blue) shift is similar to that of Brooker's merocyanine (Figure 5), a well-known dye with a ground state predominantly in the zwitterionic form. ${ }^{19}$

For the new dyes with stronger donor rings, a decrease in solvent polarity resulted in destabilization of the zwitterionic form and moved the dye ground state toward the "cyanine limit", increasing the contribution from the nonpolar form. The calculated central $\mathrm{C}-\mathrm{C}$ bond lengths of the ground-state geometries are presented in Table 3. Obviously, the solute structures vary with solvent polarity. Strong bond length alternations (BLA) were found for merocyanines $\mathbf{2 a}-\mathbf{c}$ in $\mathrm{MeOH}$, where dyes predominantly exist as zwitterions. The alternations were diminished in benzene, indicating a ground state more like the "cyanine limit". For I-TBA and I-SO, the average BLA was small, suggesting that in both solvents the ground states of the dyes are close to the cyanine limit.

The structural changes of the solutes with increasing solvent polarity from $\mathrm{C}_{6} \mathrm{H}_{6}$ are consistent with the changes of the solute dipole moment (Table 4$)$. The $S_{0}$ state dipole moments $\left(\mu_{\mathrm{S} 0}\right)$ are increased moderately by 6.15 and $4.57 \mathrm{D}$ for I-TBA and I-SO, and significantly by $9.70,8.82$, and $8.45 \mathrm{D}$ for AI-TBA(4), AI-BA(4), and AI-SO(4), respectively, from $\mathrm{C}_{6} \mathrm{H}_{6}$ to $\mathrm{MeOH}$ solutions.

The change of the solute dipole moment in different solutions, or upon $S_{0} \rightarrow S_{1}$ transitions, is caused by charge rearrangement or intramolecular charge transfer. We present in Figure 6 the

TABLE 2: Observed Absorption Properties of Dyes 1a,b, 2a-d, 3, and 4

\begin{tabular}{|c|c|c|c|c|c|c|c|c|}
\hline solvent & $\begin{array}{c}\mathbf{3} \\
\mathbf{I - T B A} \\
\lambda_{\max } / \mathrm{nm} \\
(\epsilon) \\
\end{array}$ & $\begin{array}{c}\mathbf{4} \\
\mathbf{I - S O} \\
\lambda_{\max } / \mathrm{nm} \\
(\epsilon) \\
\end{array}$ & $\begin{array}{c}\mathbf{2 a} \\
\mathbf{A I - S O}(\mathbf{4}) \\
\lambda_{\max } / \mathrm{nm} \\
(\epsilon)\end{array}$ & $\begin{array}{c}\mathbf{2 b} \\
\mathbf{A I - B A}(\mathbf{4}) \\
\lambda_{\max } / \mathrm{nm} \\
(\epsilon)\end{array}$ & $\begin{array}{c}\mathbf{2 c} \\
\mathbf{A I - T B A}(4) \\
\lambda_{\max } / \mathrm{nm} \\
(\epsilon) \\
\end{array}$ & $\begin{array}{c}\mathbf{2 d} \\
\mathbf{P - S O}(4) \\
\lambda_{\max } / \mathrm{nm} \\
(\epsilon) \\
\end{array}$ & $\begin{array}{c}\mathbf{1 a} \\
\mathbf{P - S O}(2) \\
\lambda_{\max } / \mathrm{nm} \\
(\epsilon) \\
\end{array}$ & $\begin{array}{c}\mathbf{1 b} \\
\mathbf{A I - S O}(\mathbf{2}) \\
\lambda_{\max } / \mathrm{nm} \\
(\epsilon) \\
\end{array}$ \\
\hline $\mathrm{MeOH}$ & $\begin{array}{l}583 \\
(173000)\end{array}$ & $\begin{array}{l}586 \\
(143000)\end{array}$ & $\begin{array}{l}610 \\
(65000)\end{array}$ & $\begin{array}{l}585 \\
(83000)\end{array}$ & $\begin{array}{l}576 \\
(38000)\end{array}$ & $\begin{array}{l}580 \\
(54000)\end{array}$ & $\begin{array}{l}505 \\
(57000)\end{array}$ & $\begin{array}{l}542 \\
(92000)\end{array}$ \\
\hline $\mathrm{EtOH}$ & & & $\begin{array}{l}636 \\
(83000)\end{array}$ & $\begin{array}{l}604 \\
(104000)\end{array}$ & $\begin{array}{l}603 \\
(46000)\end{array}$ & $\begin{array}{l}557 \\
(61000)\end{array}$ & $\begin{array}{l}514 \\
(65000)\end{array}$ & $\begin{array}{l}549 \\
(111000)\end{array}$ \\
\hline$i$-PrOH & & & $\begin{array}{l}648 \\
(122000)\end{array}$ & $\begin{array}{l}614 \\
(132000)\end{array}$ & $\begin{array}{l}618 \\
(50000)\end{array}$ & $\begin{array}{l}597 \\
(68000)\end{array}$ & $\begin{array}{l}518 \\
(72000)\end{array}$ & $\begin{array}{l}553 \\
(132000)\end{array}$ \\
\hline $\mathrm{BuOH}$ & $\begin{array}{l}589 \\
(190000)\end{array}$ & $\begin{array}{l}587 \\
(134000)\end{array}$ & $\begin{array}{l}650 \\
(118000)\end{array}$ & $\begin{array}{l}615 \\
(154000)\end{array}$ & $\begin{array}{l}619 \\
(53000)\end{array}$ & $\begin{array}{l}593 \\
(64000)\end{array}$ & $\begin{array}{l}519 \\
(67000)\end{array}$ & $\begin{array}{l}554 \\
(120000)\end{array}$ \\
\hline $\mathrm{OcOH}$ & $\begin{array}{l}590 \\
(180000)\end{array}$ & $\begin{array}{l}587 \\
(125000)\end{array}$ & $\begin{array}{l}660 \\
(150000)\end{array}$ & $\begin{array}{l}628 \\
(143000)\end{array}$ & $\begin{array}{l}633 \\
(97000)\end{array}$ & $\begin{array}{l}612 \\
(80000)\end{array}$ & $\begin{array}{l}524 \\
(72000)\end{array}$ & $\begin{array}{l}559 \\
(150000)\end{array}$ \\
\hline DMF & $\begin{array}{l}589 \\
(183000)\end{array}$ & $\begin{array}{l}586 \\
(143000)\end{array}$ & $\begin{array}{l}651 \\
(154000)\end{array}$ & $\begin{array}{l}625 \\
(146000)\end{array}$ & $\begin{array}{l}616 \\
(52000)\end{array}$ & $\begin{array}{l}604 \\
(99000)\end{array}$ & $\begin{array}{l}522 \\
(92000)\end{array}$ & $\begin{array}{l}556 \\
(157000)\end{array}$ \\
\hline DMSO & & & $\begin{array}{l}644 \\
(118000)\end{array}$ & $\begin{array}{l}617 \\
(122000)\end{array}$ & $\begin{array}{l}607 \\
(56000)\end{array}$ & $\begin{array}{l}599 \\
(77000)\end{array}$ & $\begin{array}{l}520 \\
(75000)\end{array}$ & $\begin{array}{l}555 \\
(126000)\end{array}$ \\
\hline $\mathrm{CH}_{3} \mathrm{CN}$ & & & $\begin{array}{l}642 \\
(142000)\end{array}$ & $\begin{array}{l}621 \\
(141000)\end{array}$ & $\begin{array}{l}615 \\
(54000)\end{array}$ & $\begin{array}{l}596 \\
(93000)\end{array}$ & $\begin{array}{l}546 \\
(89000)\end{array}$ & $\begin{array}{l}549 \\
(149000)\end{array}$ \\
\hline $\mathrm{CH}_{2} \mathrm{Cl}_{2}$ & & & $\begin{array}{l}667 \\
(278000)\end{array}$ & $\begin{array}{l}647 \\
(224000)\end{array}$ & $\begin{array}{l}655 \\
(104000)\end{array}$ & $\begin{array}{l}629 \\
(187000)\end{array}$ & $\begin{array}{l}529 \\
(128000)\end{array}$ & $\begin{array}{l}561 \\
(218000)\end{array}$ \\
\hline $\mathrm{C}_{6} \mathrm{H}_{6}$ & $\begin{array}{l}584 \\
(127000)\end{array}$ & $\begin{array}{l}571 \\
(109000)\end{array}$ & $\begin{array}{l}679 \\
(240000)\end{array}$ & $\begin{array}{l}662 \\
(201000)\end{array}$ & $\begin{array}{l}683 \\
(135000)\end{array}$ & $\begin{array}{l}644 \\
(178000)\end{array}$ & $\begin{array}{l}538 \\
(169000)\end{array}$ & $\begin{array}{l}570 \\
(235000)\end{array}$ \\
\hline
\end{tabular}


Al-SO(4)

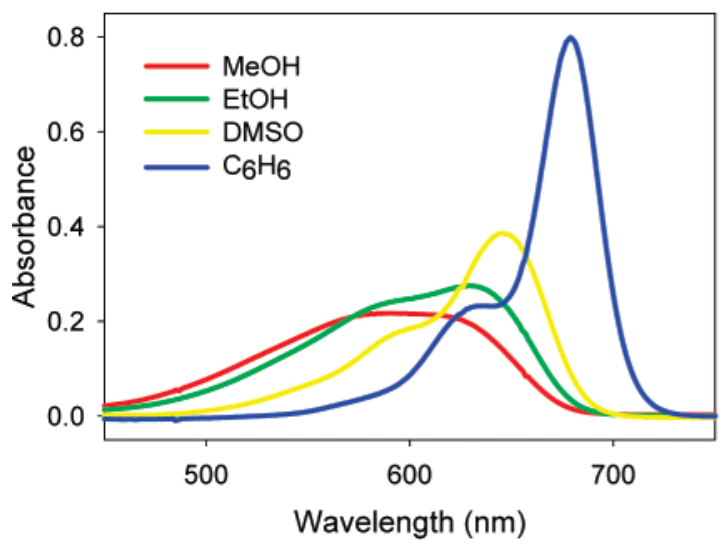

Al-BA(4)

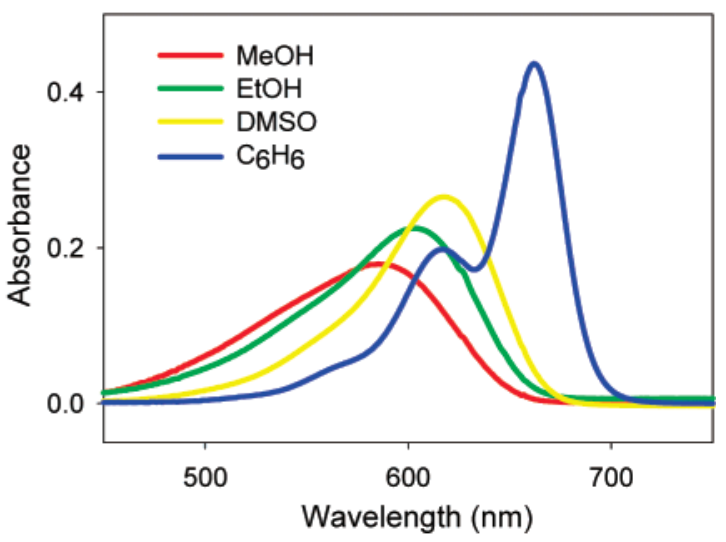

Figure 4. Absorbance spectra of AI-BA(4) and AI-SO(4) in methanol, ethanol, DMSO, and benzene. C(AI-BA(4)) $=2.17$ iM, C(AI-SO(4)) $=$ $3.33 \mu \mathrm{M}$.<smiles>CC[CH]Oc1ccc(/C=C/C2=CC[NH+](C)C=C2)cc1</smiles>

Figure 5. Brooker's merocyanine.

molecular orbital plots for the electron in the HOMO of the $S_{0}$ state and the $\pi \rightarrow \pi^{*}$ promoted electron in the $S_{1}$ state of dye 2b, AI-BA(4) in $\mathrm{C}_{6} \mathrm{H}_{6}$ and in $\mathrm{MeOH}$. The contributions of the atomic $\pi$-orbitals to the $\mathrm{HOMO}$ vary with solvent type. In $\mathrm{C}_{6} \mathrm{H}_{6}$ solution, the electron in the HOMO is mainly localized at $\mathrm{C}_{7}$ (17.2\%), $\mathrm{C}_{3}(17.0 \%), \mathrm{C}_{5}(16.3 \%), \mathrm{N}_{18}(6.6 \%), \mathrm{C}_{16}(5.2 \%), \mathrm{O}_{11}$ (4.6\%), $\mathrm{C}_{1}(4.2 \%), \mathrm{O}_{10}(3.8 \%)$, and $\mathrm{C}_{2}(2.5 \%)$. In $\mathrm{MeOH}$ solution, the localization of the electron in the HOMO is shifted rightward and localized at the atoms of $\mathrm{C}_{3}(17.7 \%), \mathrm{C}_{7}(17.3 \%)$, $\mathrm{C}_{5}(16.6 \%), \mathrm{N}_{18}(5.3 \%), \mathrm{O}_{11}(5.0 \%), \mathrm{C}_{16}(4.7 \%), \mathrm{O}_{10}(4.2 \%)$, $\mathrm{C}_{1}(4.2 \%), \mathrm{C}_{6}(3.4 \%)$, and $\mathrm{O}_{15}(2.4 \%)$. Not only the electron in the HOMO but also the distribution of other electrons varies with solvent polarity; therefore, the dipole moment of $S_{0}$ state AI-BA(4) is substantially increased with increasing solvent polarity from $\mathrm{C}_{6} \mathrm{H}_{6}$ to $\mathrm{MeOH}$. During the $\pi \rightarrow \pi^{*}$ transition, the solute dipole moment decreases. The promoted electron in the $\pi^{*}$ orbital moved leftward. In $\mathrm{C}_{6} \mathrm{H}_{6}$ solution, it is mainly localized at the atoms of $\mathrm{C}_{4}(14.1 \%), \mathrm{C}_{2}(14.0 \%), \mathrm{C}_{6}(13.6 \%)$, $\mathrm{C}_{19}(9.7 \%), \mathrm{N}_{18}(7.2 \%), \mathrm{C}_{17}(5.4 \%), \mathrm{C}_{5}(5.1 \%), \mathrm{C}_{23}(3.2 \%), \mathrm{O}_{10}$ (3.1\%), $\mathrm{C}_{25}(3.1 \%), \mathrm{C}_{8}(3.1 \%)$, and $\mathrm{O}_{11}(2.9 \%)$ for the vertical $S_{1}$ state. In $\mathrm{MeOH}$, the contributions change to $\mathrm{C}_{4}(14.4 \%), \mathrm{C}_{6}$ (13.9\%), $\mathrm{C}_{2}(13.0 \%), \mathrm{N}_{18}(8.9 \%), \mathrm{C}_{19}(8.7 \%), \mathrm{C}_{17}(5.5 \%), \mathrm{C}_{16}$ $(4.9 \%), \mathrm{C}_{3}(3.6 \%), \mathrm{C}_{23}(3.1 \%), \mathrm{C}_{8}(3.0 \%), \mathrm{C}_{25}(2.9 \%)$, and $\mathrm{C}_{9}$ $(2.7 \%)$.
When the solute dipole moment in the excited state is larger than that in the ground state, the excited state is better stabilized in polar solvents relative to the ground state. With increasing solvent polarity, there will be a red shift for the absorption bands. On the other hand, a blue shift with increasing solvent polarity will occur if the solute dipole moment in the ground state is larger than that in the excited state. During the $\pi \rightarrow \pi^{*}$ excitation process, the solute dipole moments of AI-TBA(4), AI-BA(4), and $\mathrm{AI}-\mathrm{SO}(4)$ all decrease in $\mathrm{MeOH}$ solution (Table 4). Their absorption bands shift to the blue with increasing solvent polarity from $\mathrm{C}_{6} \mathrm{H}_{6}$ to $\mathrm{MeOH}$. By contrast, the dipole moment of I-SO increases during the $\pi \rightarrow \pi^{*}$ transition, and we observe the red shift of its absorption band from $\mathrm{C}_{6} \mathrm{H}_{6}$ to $\mathrm{MeOH}$ solution.

In Table 4, we also present the SCRF/VSCRF calculated vertical excitation energies of these molecules. The $\triangle \mathrm{SCF}$ procedure of DFT method normally underestimates the absolute value of the $S_{1}$ state energy and therefore also the vertical excitation energy. ${ }^{19,20}$ However, the directions and approximate magnitudes of the solvatochromic shift are correctly predicted. Experimentally, we observed a very small red shift for I-TBA with increasing solvent polarity from $\mathrm{C}_{6} \mathrm{H}_{6}$ to $\mathrm{OcOH}$ (with $\Delta E_{\mathrm{abs}}$ $=0.021 \mathrm{eV}$, or $\left.\Delta \lambda_{\max }=6 \mathrm{~nm}\right)$. We did predict a slight red shift for this molecule from $\mathrm{C}_{6} \mathrm{H}_{6}$ to $\mathrm{MeOH}$ (with $\Delta E_{\text {abs }}=0.012$ $\mathrm{eV}$ ). The observed blue shift from $\mathrm{OcOH}$ to $\mathrm{MeOH}$ solutions $\left(\Delta \lambda_{\max }=7 \mathrm{~nm}\right)$ is possibly caused by the explicit interactions (for instance, H-bonding interactions) between the solute and solvent molecules.
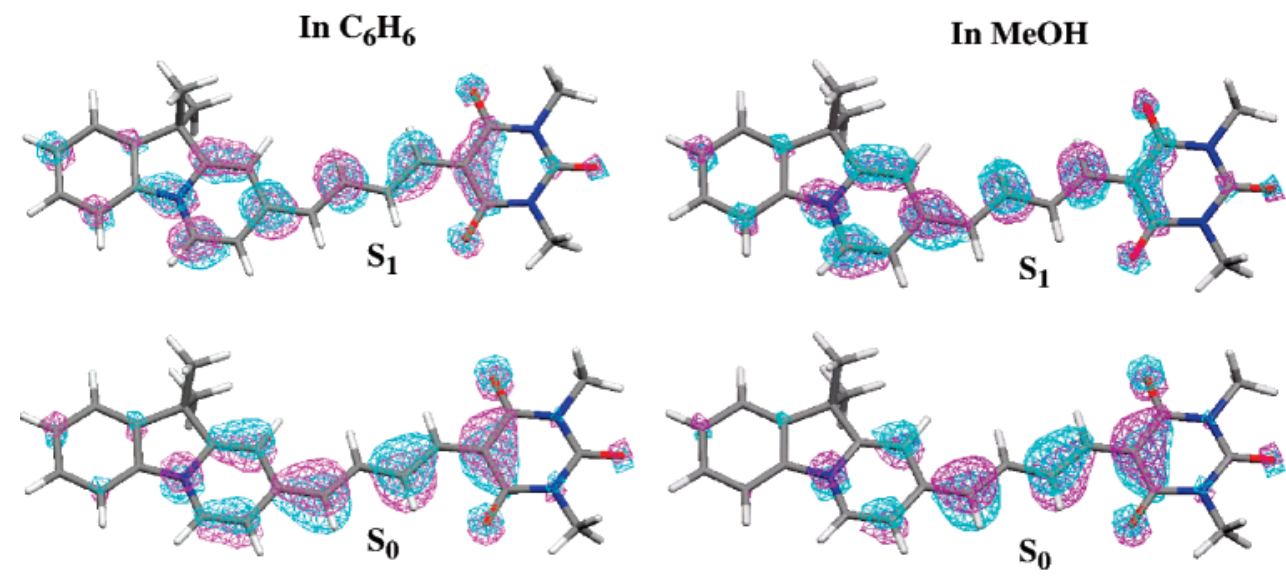

Figure 6. Molecular orbital plots for the electron in the HOMO of the ground state $\left(S_{0}\right)$ and the $\pi \rightarrow \pi^{*}$ promoted electron in the first excited singlet state of $\mathrm{AI}-\mathrm{BA}(4)$ in $\mathrm{C}_{6} \mathrm{H}_{6}$ and in $\mathrm{MeOH}$. 
TABLE 3: DFT-Calculated Central C-C Bond Lengths $(\AA)$ of the Ground-State Dye Molecules in $\mathrm{C}_{6} \mathrm{H}_{6}$ and in $\mathrm{MeOH}$

\begin{tabular}{|c|c|c|c|c|c|c|}
\hline \multirow[b]{2}{*}{ solvent } & \multirow[b]{2}{*}{ bond } & \multicolumn{5}{|c|}{ solute } \\
\hline & & I-TBA & AI-TBA(4) & AI-BA(4) & I-SO & $\mathrm{AI}-\mathrm{SO}(4)$ \\
\hline \multirow[t]{5}{*}{$\mathrm{C}_{6} \mathrm{H}_{6}$} & $\mathrm{C}_{2}-\mathrm{C}_{3}$ & 1.394 & 1.413 & 1.411 & 1.386 & 1.412 \\
\hline & $\mathrm{C}_{3}-\mathrm{C}_{4}$ & 1.404 & 1.403 & 1.404 & 1.409 & 1.395 \\
\hline & $\mathrm{C}_{4}-\mathrm{C}_{5}$ & 1.393 & 1.403 & 1.401 & 1.383 & 1.394 \\
\hline & $\mathrm{C}_{5}-\mathrm{C}_{6}$ & 1.397 & 1.396 & 1.399 & 1.404 & 1.401 \\
\hline & $\mathrm{C}_{6}-\mathrm{C}_{7}$ & 1.402 & 1.408 & 1.404 & 1.382 & 1.386 \\
\hline $\operatorname{BLA}\left(\mathrm{C}_{6} \mathrm{H}_{6}\right)^{a}$ & & 0.007 & 0.009 & 0.010 & 0.022 & 0.005 \\
\hline \multirow{5}{*}{$\mathrm{MeOH}$} & $\mathrm{C}_{2}-\mathrm{C}_{3}$ & 1.401 & 1.430 & 1.427 & 1.398 & 1.429 \\
\hline & $\mathrm{C}_{3}-\mathrm{C}_{4}$ & 1.395 & 1.389 & 1.393 & 1.399 & 1.382 \\
\hline & $\mathrm{C}_{4}-\mathrm{C}_{5}$ & 1.402 & 1.419 & 1.416 & 1.396 & 1.410 \\
\hline & $\mathrm{C}_{5}-\mathrm{C}_{6}$ & 1.390 & 1.384 & 1.387 & 1.396 & 1.388 \\
\hline & $\mathrm{C}_{6}-\mathrm{C}_{7}$ & 1.415 & 1.426 & 1.421 & 1.395 & 1.404 \\
\hline $\mathrm{BLA}(\mathrm{MeOH})^{a}$ & & 0.009 & 0.038 & 0.032 & 0.0005 & 0.035 \\
\hline
\end{tabular}

${ }^{a} \mathrm{BLA}=\left\{\left|\left(\mathrm{C}_{2}-\mathrm{C}_{3}\right)-\left(\mathrm{C}_{3}-\mathrm{C}_{4}\right)\right|+\left|\left(\mathrm{C}_{4}-\mathrm{C}_{5}\right)-\left(\mathrm{C}_{5}-\mathrm{C}_{6}\right)\right|\right\} / 2$.

TABLE 4: SCRF/VSCRF Calculated and Experimentally (Expt) Observed Absorption $\left(E_{\text {abs }}\right)$ Energies $(e V)$ and the Relaxed $S_{0}$ State $\left(\mu_{\mathrm{S} 0}\right)$ and Vertical $S_{1}\left(\mu_{\mathrm{S} 1}^{\mathrm{v}}\right)$ State Dipole Moments (D) for the Dyes in $\mathrm{C}_{6} \mathrm{H}_{6}$ and in MeOH; TDDFT Calculated Absorption Energies (eV) for AI-BA(4) Are Also Given Here

\begin{tabular}{|c|c|c|c|c|c|c|}
\hline \multicolumn{7}{|c|}{ absorption } \\
\hline \multirow[b]{2}{*}{ solute } & \multirow[b]{2}{*}{ solvent } & \multirow[b]{2}{*}{$\mu_{\mathrm{S} 0}$} & \multirow[b]{2}{*}{$\mu_{\mathrm{S} 1}^{\mathrm{v}}$} & \multicolumn{3}{|c|}{$E_{\text {abs }}$} \\
\hline & & & & SCRF/VSCRF & TDDFT & expt \\
\hline \multirow[t]{2}{*}{ I-TBA } & $\mathrm{C}_{6} \mathrm{H}_{6}$ & 16.53 & 17.86 & 1.611 & & $2.123(585 \mathrm{~nm})$ \\
\hline & $\mathrm{MeOH}$ & 22.68 & 22.60 & 1.599 & & $2.127(583 \mathrm{~nm})$ \\
\hline \multirow{2}{*}{ AI-TBA(4) } & $\mathrm{C}_{6} \mathrm{H}_{6}$ & 22.84 & 19.77 & 1.349 & & $1.816(683 \mathrm{~nm})$ \\
\hline & $\mathrm{MeOH}$ & 32.54 & 25.19 & 1.581 & & $2.153(576 \mathrm{~nm})$ \\
\hline \multirow[t]{2}{*}{ AI-BA(4) } & $\mathrm{C}_{6} \mathrm{H}_{6}$ & 19.78 & 18.46 & 1.411 & 2.347 & $1.873(662 \mathrm{~nm})$ \\
\hline & $\mathrm{MeOH}$ & 28.60 & 21.60 & 1.583 & 2.373 & $2.120(585 \mathrm{~nm})$ \\
\hline \multirow[t]{2}{*}{ I-SO } & $\mathrm{C}_{6} \mathrm{H}_{6}$ & 10.07 & 16.91 & 1.637 & & $2.172(571 \mathrm{~nm})$ \\
\hline & $\mathrm{MeOH}$ & 14.64 & 17.63 & 1.556 & & $2.116(586 \mathrm{~nm})$ \\
\hline \multirow[t]{2}{*}{$\mathrm{AI}-\mathrm{SO}(4)$} & $\mathrm{C}_{6} \mathrm{H}_{6}$ & 17.71 & 18.56 & 1.401 & & $1.826(679 \mathrm{~nm})$ \\
\hline & $\mathrm{MeOH}$ & 26.16 & 23.83 & 1.536 & & $2.120(585 \mathrm{~nm})$ \\
\hline
\end{tabular}

Recently, solvent continuum models for predicting the vertical electronic transitions have also been established at the timedependent DFT (TDDFT) level. ${ }^{41-46}$ Calculations on the $\mathrm{n} \rightarrow$ $\pi^{*}$ transition energies of diazines performed by Mennucci ${ }^{42}$ and Cossi and Barone ${ }^{44}$ have shown results that are in very good agreement with the experiments. However, calculations with TDDFT are still not straightforward in the optimization of geometries on the excited-state surfaces. To compare the SCRF/ VSCRF and the TDDFT methods, we also applied SCRF/ VSCRF calculations on the diazines (Figure 1 of ref 19) to predict the blue shifts with increasing solvent polarities from $n$-heptane to water solutions ${ }^{19}$ and compared our results with the TDDFT $^{44}$ and the experimental data. ${ }^{47} \mathrm{We}$ saw that the TDDFT method was better than the $\triangle \mathrm{SCF}$ calculations in predicting the absolute values of the vertical excitation energies. However, the blue shifts from $n$-heptane to water obtained by SCRF/VSCRF calculations are much closer to those from the experimental data than those from the TDDFT results, especially for pyridazine and pyrimidine. ${ }^{19}$ Both SCRF/VSCRF and TDDFT calculations show that consideration of the explicit water H-bonding effects is very important to predict the correct blue shifts for diazines from $n$-heptane to water. ${ }^{19}$

According to the ADF manual, it is possible to combine the COSMO model with TDDFT calculations. The usually major effects (modified zeroth-order Kohn-Sham (KS) orbitals and orbital energies) are included. However, COSMO should also modify the first-order change in the KS potential. This effect has not yet been implemented in ADF and may be significant in case of a high value of the dielectric constant. To see if we can use this TDDFT version in our dye calculations in different solvents, we applied the combination of COSMO and TDDFT at the COSMO-optimized geometries of $S_{0}$ state AI-BA(4). The results are also given in Table 4 . As seen before, the absolute values of the excitation energies predicted by TDDFT are much larger than those of the $\triangle \mathrm{SCF}$ calculations ${ }^{19}$ and larger than the experimental spectral energies in the current case. The TDDFT calculations yield very similar excitation energies for $\mathrm{AI}-\mathrm{BA}(4)$ in $\mathrm{C}_{6} \mathrm{H}_{6}$ and in $\mathrm{MeOH}$. The energy difference is only $0.026 \mathrm{eV}$, which is much worse than the SCRF/VSCRF's result $(0.172 \mathrm{eV})$ compared with that of the experiment $(0.247$ $\mathrm{eV})$.

3.3. Broadening of Dye Absorption in Alcohols; Role of H-Bonding. The dyes studied here have very broad absorption bands in polar, hydrogen-bonding solvents such as methanol or ethanol (Figure 4). It is known that the width of a band in the absorption spectrum of a chromophore in solution is a result of two effects: homogeneous and inhomogeneous broadening.

Homogeneous broadening is due to the existence of a continuous set of vibrational sublevels in each electronic state. The homogeneous broadening becomes important for dyes with ground states lying far from the cyanine limit. This can be understood by considering that a large amount of charge transfer will result in a large displacement of the excited-state potential surface along the solvent reorganization coordinate, leading to a larger degree of direct absorption into higher vibronic levels in the excited state. ${ }^{18}$ Inhomogeneous broadening results from the fluctuation of the structure of the solvation shell surrounding the solute. In $\mathrm{MeOH}$ solution, there will be more explicit interactions between the solute and the surrounding solvent molecules through $\mathrm{H}$-bonding. Different patterns and numbers of H-bonding interactions may result in a distribution of solutesolvent configurations. The consequent variation in the local 


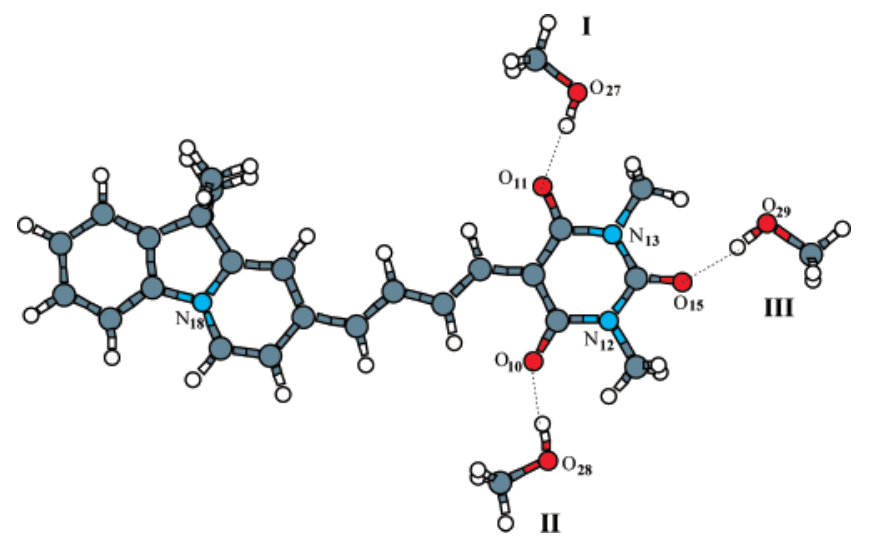

Figure 7. Three possible positions of the explicit $\mathrm{CH}_{3} \mathrm{OH}$ molecules $\mathrm{H}$-bonding to $\mathrm{AI}-\mathrm{BA}(4)$ in $\mathrm{MeOH}$ solution.

TABLE 5: Main Bond Lengths ( $⿱$ A) of the $S_{0}$ State AI-BA(4) Structure in $\mathrm{MeOH}$ with Zero, One, Two, and Three Explicit H-Bonding $\mathrm{CH}_{3} \mathrm{OH}$ Molecules ${ }^{a}$

\begin{tabular}{ccccc}
\hline bond & $+0 \mathrm{CH}_{3} \mathrm{OH}$ & $+1 \mathrm{CH}_{3} \mathrm{OH}(\mathrm{I})$ & $\begin{array}{c}+2 \mathrm{CH}_{3} \mathrm{OH}- \\
(\mathrm{I}, \mathrm{II})\end{array}$ & $\begin{array}{c}+3 \mathrm{CH}_{3} \mathrm{OH}- \\
(\mathrm{I}, \mathrm{II}, \mathrm{III})\end{array}$ \\
\hline $\mathrm{C}_{2}-\mathrm{C}_{3}$ & 1.427 & 1.435 & 1.443 & 1.444 \\
$\mathrm{C}_{3}-\mathrm{C}_{4}$ & 1.393 & 1.382 & 1.381 & 1.380 \\
$\mathrm{C}_{4}-\mathrm{C}_{5}$ & 1.416 & 1.414 & 1.418 & 1.418 \\
$\mathrm{C}_{5}-\mathrm{C}_{6}$ & 1.387 & 1.385 & 1.384 & 1.383 \\
$\mathrm{C}_{6}-\mathrm{C}_{7}$ & 1.421 & 1.420 & 1.424 & 1.425 \\
$\mathrm{C}_{7}-\mathrm{C}_{8}$ & 1.451 & 1.445 & 1.442 & 1.441 \\
$\mathrm{C}_{7}-\mathrm{C}_{9}$ & 1.450 & 1.445 & 1.447 & 1.444 \\
$\mathrm{C}_{1}-\mathrm{C}_{19}$ & 1.369 & 1.373 & 1.373 & 1.373 \\
$\mathrm{C}_{16}-\mathrm{C}_{17}$ & 1.371 & 1.385 & 1.390 & 1.390
\end{tabular}

${ }^{a}$ See atomic labels of AI-BA(4) in Chart 2 and the $\mathrm{CH}_{3} \mathrm{OH}$ molecular positions of I, II, and III in Figure 7. Geometries were optimized using the COSMO model in ADF.

electric field leads to a statistical distribution of energies of the electronic transitions. Also, upon excitation, different solute structures and energies may result from the $v=0$ vibrational level in $S_{0}$ to $v=n$ transitions in the $S_{1}$ state. Therefore, the broad absorption bands in $\mathrm{MeOH}$ solution result from homogeneous and inhomogeneous effects. According to our isomer geometry and energy calculations given in section 3.1, different isomers of a certain dye may coexist in a certain solvent. In polar solvents such as $\mathrm{MeOH}$, different isomers will have different $\mathrm{H}$-bonding interactions with the solvent molecules, which is also a source for the inhomogeneous broadening.

To see how explicit H-bonding and different numbers of $\mathrm{H}$-bonding interactions influence the solute structure and properties, we took $\mathrm{AI}-\mathrm{BA}(4)$ as an example and put one, two, and three explicit $\mathrm{CH}_{3} \mathrm{OH}$ molecules $\mathrm{H}$-bonding to the solute in different positions (Figure 7). The $+1 \mathrm{CH}_{3} \mathrm{OH}(\mathrm{I})$ model contains one $\mathrm{CH}_{3} \mathrm{OH}$ molecule at position I, the $+2 \mathrm{CH}_{3} \mathrm{OH}$ (I,II) model has two $\mathrm{CH}_{3} \mathrm{OH}$ molecules in total at positions I and II, and the $+3 \mathrm{CH}_{3} \mathrm{OH}(\mathrm{I}, \mathrm{II}, \mathrm{III})$ model contains all three $\mathrm{H}$-bonding $\mathrm{CH}_{3} \mathrm{OH}$ molecules at I, II, and III, respectively. The geometries were then optimized using the COSMO model in ADF.

The main bond lengths of these structures are given in Table 5. For comparison, we also include the values for the structure without explicit H-bonding partners. Clearly, the geometry of AI-BA(4) changes upon interaction with the solvent molecule and also changes with increasing numbers of the H-bonding solvent molecules. First, we look at the central $\mathrm{C}-\mathrm{C}$ bonds. Without including explicit $\mathrm{H}$-bonding interactions, the $\mathrm{C}_{2}-\mathrm{C}_{3}$, $\mathrm{C}_{3}-\mathrm{C}_{4}, \mathrm{C}_{4}-\mathrm{C}_{5}, \mathrm{C}_{5}-\mathrm{C}_{6}$, and $\mathrm{C}_{6}-\mathrm{C}_{7}$ bond lengths are 1.427, $1.393,1.416,1.387$, and $1.421 \AA$, respectively, with obvious single, double, single, double, and single bond characters, consistent with Chart 1. By including one and two H-bonding $\mathrm{CH}_{3} \mathrm{OH}$ molecules, these bonding characters are strengthened, with $\mathrm{C}_{2}-\mathrm{C}_{3}, \mathrm{C}_{4}-\mathrm{C}_{5}$, and $\mathrm{C}_{6}-\mathrm{C}_{7}$ lengthened and $\mathrm{C}_{3}-\mathrm{C}_{4}$ and $\mathrm{C}_{5}-\mathrm{C}_{6}$ shortened. In the $+3 \mathrm{CH}_{3} \mathrm{OH}(\mathrm{I}$,II,III) model, the bond lengths of $\mathrm{C}_{2}-\mathrm{C}_{3}, \mathrm{C}_{4}-\mathrm{C}_{5}$, and $\mathrm{C}_{6}-\mathrm{C}_{7}$ reach the largest values of $1.444,1.418$, and $1.425 \AA$, and $\mathrm{C}_{3}-\mathrm{C}_{4}$ and $\mathrm{C}_{5}-\mathrm{C}_{6}$ are the shortest bonds 1.380 and $1.383 \AA$, respectively, among the calculated models. By including explicit $\mathrm{H}$-bonding interactions, the bonding characters of $\mathrm{C}_{1}-\mathrm{C}_{19}$ and $\mathrm{C}_{16}-\mathrm{C}_{17}$ are weakened, and those of $\mathrm{C}_{7}-\mathrm{C}_{8}$ and $\mathrm{C}_{7}-\mathrm{C}_{9}$ are strengthened.

The SCRF/VSCRF calculated dipole moment values and vertical excitation energies for these models are given in Table 6. We see that the dipole moment of the solute increases with increasing number of $\mathrm{H}$-bonding solvent molecules. Different models in $\mathrm{MeOH}$ produce different absorption energies $\left(E_{\mathrm{abs}}\right)$, and the $E_{\text {abs }}$ value increases with increasing numbers of the H-bonding solvent molecules. In reality, the orientation and the number of the $\mathrm{H}$-bonding interactions between the solute and the solvent molecules may vary and be different from our models. However, our calculations here show that the absorption energy of the solute is influenced by the number and patterns of H-bonding interactions. The excitation energy differences we predicted among the different $\mathrm{MeOH} \mathrm{H}$-bonding models are not as large as the broadening we observed experimentally. The inhomogeneous broadening includes molecular dynamics effects that we have not taken into account and homogeneous broadening as well.

We note that our calculations correspond to $S_{0}(v=0) \rightarrow S_{1}$ vertical transitions. Specifically for absorption, these calculations are performed in the optimal ground-state geometry, and the excited state is calculated in the same geometry, assuming the Frank-Condon principle. In reality, the $S_{0}(v=0) \rightarrow S_{1}(v=n)$ ( $n$ is largely unidentified) transitions from a distribution of solute-solvent configurations will result in a large span of excitation energies.

In Table 6, we also compared the SCRF/VSCRF calculated and observed energy difference of $E_{\mathrm{abs}}(\mathrm{MeOH})-E_{\mathrm{abs}}\left(\mathrm{C}_{6} \mathrm{H}_{6}\right)$, which represents the blue shift of the absorption band of AI-BA(4) with increasing solvent polarity from $\mathrm{C}_{6} \mathrm{H}_{6}$ to $\mathrm{MeOH}$. The predicted energy shift gets closer to the experimental value each time we add one, two, and three explicit $\mathrm{H}$-bonding $\mathrm{CH}_{3}-$ $\mathrm{OH}$ molecules into the quantum region. Especially when considering three $\mathrm{H}$-bonding $\mathrm{CH}_{3} \mathrm{OH}$ molecules, our predicted energy shift $0.237 \mathrm{eV}$ is in very good agreement with the experimental value of $0.247 \mathrm{eV}$. Again, we see it is important to take into account the possible explicit H-bonding effects in the SCRF/VSCRF calculations to predict the correct order and reasonable relative excitation energies of the solute molecule in different solvents.

For comparison, we also performed the TDDFT plus COSMO single-point energy calculations on these three COSMOoptimized AI-BA(4) structures. Results are also given in Table 6. The current TDDFT plus COSMO calculations yield essentially no difference on the $+1,+2$, and $+3 \mathrm{CH}_{3} \mathrm{OH}$ models. Having the explicit $\mathrm{H}$-bonding $\mathrm{MeOH}$ molecules with the solute, instead of increasing the blue shift from $\mathrm{C}_{6} \mathrm{H}_{6}$ to $\mathrm{MeOH}$ solvent, TDDFT predicted a decrease of the shift (which was already very small, $0.026 \mathrm{eV}$ ), making no difference of the absorption energy of AI-BA(4) in $\mathrm{C}_{6} \mathrm{H}_{6}$ and in $\mathrm{MeOH}$. The current version of the combination of TDDFT and COSMO in ADF, without modifying the first-order change in the KS potential, is therefore not suitable for solvatochromic studies. 
TABLE 6: SCRF/VSCRF- and TDDFT-Calculated Absorption (or Excitation) $\left(E_{\text {abs }}\right)$ Energies $(\mathrm{eV})$, the Relaxed $S_{0}$ State $\left(\mu_{\mathrm{S} 0}\right)$, and Vertical $S_{1}\left(\mu^{\mathrm{v}} \mathrm{S}\right)$ State Dipole Moments (D) for AI-BA(4) in Different H-Bonding Models in MeOH (Figure 7), and the Absorption Energy Shifts from $\mathrm{C}_{6} \mathrm{H}_{6}$ to $\mathrm{MeOH}$ Solvents

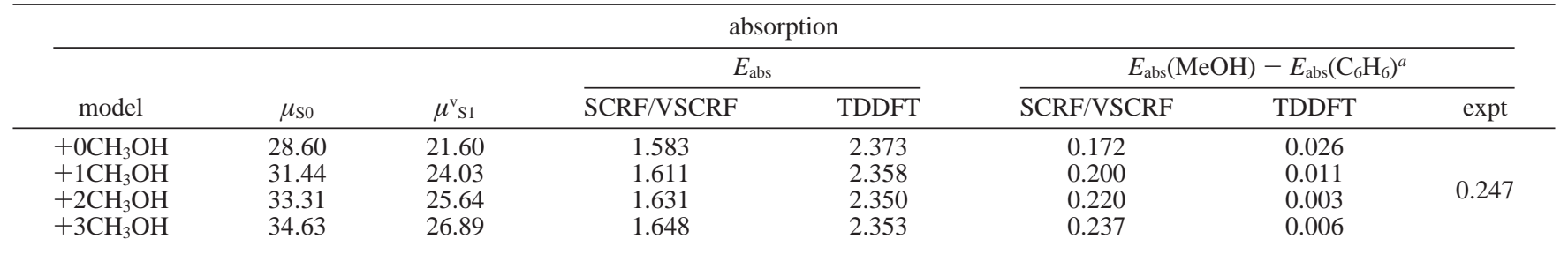

${ }^{a}$ The values of $E_{\text {abs }}(\mathrm{MeOH})$ are the $E_{\text {abs }}$ values given in the table for different models. $E_{\text {abs }}\left(\mathrm{C}_{6} \mathrm{H}_{6}\right)=1.411 \mathrm{eV}$ for VSCRF and $2.347 \mathrm{eV}$ for TDDFT, which were given in Table 4 .

TABLE 7: Observed Emission Properties of Dyes 1a,b, 2a-d, 3, and 4

\begin{tabular}{|c|c|c|c|c|c|c|c|}
\hline solvent & $\begin{array}{c}\mathbf{3} \\
\mathbf{I - T B A} \\
\lambda_{\max } / \mathrm{nm} \\
\left(\Phi^{a}\right)\end{array}$ & $\begin{array}{c}\mathbf{4} \\
\mathbf{I - S O} \\
\lambda_{\max } / \mathrm{nm} \\
(\Phi)\end{array}$ & $\begin{array}{c}\mathbf{2 a} \\
\mathbf{A I}-\mathbf{S O}(\mathbf{4}) \\
\lambda_{\max } / \mathrm{nm} \\
(\Phi)\end{array}$ & $\begin{array}{c}\mathbf{2 b} \\
\mathbf{A I}-\mathbf{B A}(\mathbf{4}) \\
\lambda_{\max } / \mathrm{nm} \\
(\Phi)\end{array}$ & $\begin{array}{c}\mathbf{2 d} \\
\mathbf{P}-\mathbf{S O}(\mathbf{4}) \\
\lambda_{\max } / \mathrm{nm} \\
(\Phi)\end{array}$ & $\begin{array}{c}\mathbf{1 a} \\
\mathbf{P}-\mathbf{S O}(\mathbf{2}) \\
\lambda_{\max } / \mathrm{nm} \\
(\Phi)\end{array}$ & $\begin{array}{c}\mathbf{1 b} \\
\mathbf{A I}-\mathbf{S O}(\mathbf{2}) \\
\lambda_{\max } / \mathrm{nm} \\
(\Phi)\end{array}$ \\
\hline $\mathrm{MeOH}$ & $603(0.26)$ & $615(0.08)$ & $665(0.54)$ & $618(0.52)$ & $630(0.018)$ & $529(0.005)$ & $561(0.05)$ \\
\hline $\mathrm{EtOH}$ & & & $671(0.82)$ & $651(0.19)$ & $634(0.029)$ & $533(0.008)$ & $563(0.09)$ \\
\hline i-PrOH & & & $673(0.96)$ & $652(0.22)$ & $636(0.049)$ & $532(0.014)$ & $565(0.13)$ \\
\hline $\mathrm{BuOH}$ & $609(0.61)$ & $618(0.54)$ & $675(0.92)$ & $654(0.29)$ & $640(0.048)$ & $535(0.015)$ & $567(0.16)$ \\
\hline $\mathrm{OcOH}$ & $609(0.99)$ & $617(0.98)$ & $679(0.88)$ & $656(0.64)$ & $644(0.082)$ & $536(0.024)$ & $569(0.21)$ \\
\hline DMF & $611(0.94)$ & $615(0.97)$ & $673(\sim 1.0)$ & $658(0.26)$ & $635(0.10)$ & $534(0.025)$ & $567(0.16)$ \\
\hline DMSO & & & $673(\sim 1.0)$ & $657(0.23)$ & $636(0.067)$ & $535(0.024)$ & $567(0.24)$ \\
\hline $\mathrm{CH}_{3} \mathrm{CN}$ & & & $667(0.75)$ & $652(0.05)$ & $632(0.067)$ & $531(0.011)$ & $561(0.06)$ \\
\hline $\mathrm{CH}_{2} \mathrm{Cl}_{2}$ & & & $681(0.54)$ & $664(0.03)$ & $650(0.082)$ & $541(0.01)$ & $571(0.06)$ \\
\hline $\mathrm{C}_{6} \mathrm{H}_{6}$ & $605(0.20)$ & $603(0.42)$ & $691(0.19)$ & $670(0.01)$ & $656(0.002)$ & $546(0.004)$ & $577(0.02)$ \\
\hline
\end{tabular}

${ }^{a}$ Fluorescence quantum yield.

TABLE 8: SCRF/VSCRF-Calculated and Experimentally Observed Emission $\left(E_{\text {em }}\right)$ Energies $(\mathrm{eV})$ and the Relaxed $S_{1}$ State $\left(\mu_{\mathrm{S} 1}\right)$ and Vertical $S_{0}\left(\mu_{\mathrm{S} 0}^{\mathrm{v}}\right)$ State Dipole Moments (D) for the Dye Molecules in $\mathrm{C}_{6} \mathrm{H}_{6}$ and in $\mathrm{MeOH}$

\begin{tabular}{|c|c|c|c|c|c|c|}
\hline \multicolumn{7}{|c|}{ emission } \\
\hline \multirow[b]{2}{*}{ solute } & \multirow[b]{2}{*}{ solvent } & & \multirow[b]{2}{*}{$\mu_{\mathrm{S} 1}$} & \multirow[b]{2}{*}{$\mu_{\mathrm{s} 0}^{\mathrm{v}}$} & \multicolumn{2}{|r|}{$E_{\mathrm{em}}$} \\
\hline & & & & & $\begin{array}{c}\text { SCRF/ } \\
\text { VSCRF }\end{array}$ & expt \\
\hline \multirow[t]{2}{*}{ I-TBA } & $\mathrm{C}_{6} \mathrm{H}_{6}$ & & 18.21 & 17.00 & 1.506 & $2.050(605 \mathrm{~nm})$ \\
\hline & $\mathrm{MeOH}$ & & 23.06 & 21.61 & 1.489 & $2.056(603 \mathrm{~nm})$ \\
\hline \multirow[t]{5}{*}{ AI-BA(4) } & $\mathrm{C}_{6} \mathrm{H}_{6}$ & & 17.27 & 20.07 & 1.341 & $1.851(670 \mathrm{~nm})$ \\
\hline & $\mathrm{MeOH}$ & +0 & 19.23 & 23.91 & 1.416 & $2.006(618 \mathrm{~nm})$ \\
\hline & & +1 & 21.37 & 26.57 & 1.426 & \\
\hline & & +2 & 23.17 & 28.26 & 1.428 & \\
\hline & & +3 & 24.16 & 29.41 & 1.432 & \\
\hline \multirow[t]{2}{*}{ I-SO } & $\mathrm{C}_{6} \mathrm{H}_{6}$ & & 16.85 & 10.55 & 1.629 & $2.056(603 \mathrm{~nm})$ \\
\hline & $\mathrm{MeOH}$ & & 17.33 & 15.55 & 1.537 & $2.016(615 \mathrm{~nm})$ \\
\hline \multirow[t]{2}{*}{ AI-SO(4) } & $\mathrm{C}_{6} \mathrm{H}_{6}$ & & 18.57 & 18.15 & 1.332 & $1.794(691 \mathrm{~nm})$ \\
\hline & $\mathrm{MeOH}$ & & 23.00 & 23.31 & 1.381 & $1.865(665 \mathrm{~nm})$ \\
\hline
\end{tabular}

3.4. Fluorescence Spectra of the Dyes. The experimental emission data for the dyes are summarized in Table 7. The SCRF/VSCRF predicted emission energies and the solute dipole moments before and after the vertical emission process are given in Table 8. The dipole moments of AI-BA(4) and AI-SO(4) are further decreased on the $S_{1}$ surface after geometry relaxation (in $\mathrm{MeOH}$ solution) and then increased during the $S_{1} \rightarrow S_{0}$ transition. This is consistent with the blue shifts of the emission bands of AI-BA(4) and AI-SO(4) with increasing solvent polarity from $\mathrm{C}_{6} \mathrm{H}_{6}$ to $\mathrm{MeOH}$. By contrast, the dipole moment of I-SO further decreases after $S_{1}$ state geometry relaxation and then decreases significantly during the vertical emission process. This is also in agreement with the red shift of the I-SO emission band with increasing solvent polarity from $\mathrm{C}_{6} \mathrm{H}_{6}$ to $\mathrm{MeOH}$. Similarly to the absorption case, we predicted a negligible red shift $\left(\Delta E_{\mathrm{em}}=0.017 \mathrm{eV}\right)$ for the emission band of I-TBA with increasing solvent polarity. In reality, a small red shift does exist from $\mathrm{C}_{6} \mathrm{H}_{6}$ to $\mathrm{DMF}$ (with $\Delta E_{\mathrm{em}}=0.020 \mathrm{eV}$ or $\Delta \lambda_{\max }=6 \mathrm{~nm}$ ). The nearly equal emission energy observed in $\mathrm{C}_{6} \mathrm{H}_{6}$ and $\mathrm{MeOH}$ may again result in the explicit interactions between the solute and solvent molecules.

For the emission energy of $\mathrm{AI}-\mathrm{BA}(4)$ in $\mathrm{MeOH}$, the $E_{\mathrm{em}}$ values also increase with increasing number of the $\mathrm{H}$-bonding solvent molecules. The increment, however, is much less than the corresponding ones in the absorption process. This may also be explained by the smaller change of the dipole moment $\mu_{\mathrm{S} 1}$ from one model to another, compared with the corresponding change of $\mu_{\mathrm{s} 0}$. This may also be why the width of the emission band in $\mathrm{MeOH}$ is not as broad as the absorption band.

3.5. Fluorescence Quantum Yield. The fluorescence quantum yield $(\Phi)$ is determined by the competition between fluorescence and nonradiative pathways. Many factors can affect the fluorescence quantum yield, such as temperature (which influences the intramolecular vibrations, rotations or isomerizations, and the collisions of the solute and solvent, etc.), $\mathrm{pH}$, polarity, viscosity, hydrogen bonding, presence of quenchers, and formation of new complex. ${ }^{48}$

The main nonfluorescent deactivation path for the excited state of merocyanine 540 (MC 540), which is closely related to our dyes, is photoisomerization around the central double bond. ${ }^{49-51}$ It was supposed that partial rotation around the double bond in the excited state of MC 540 will result in formation of a perpendicular transition state that collapses to a highly excited vibronic level of the ground state, with consequent thermal dissipation of energy. ${ }^{49}$ Work with structurally similar dyes has established that, in a given solvent, the height of the barrier to internal rotation decreases with decreasing bond order of isomerizing bond. ${ }^{50}$

The quantum yield of fluorescence of MC 540 increases with increase in solvent shear viscosity, a trend that is true for dyes $\mathbf{1 a}, \mathbf{b}, \mathbf{2} \mathbf{a}-\mathbf{d}, \mathbf{3}$, and $\mathbf{4}$ (Table 7), suggesting the importance of photoisomerization for our dyes. It has been previously shown that the rate of photoisomerization of MC 540 can be correlated to solvent polarity. For example, in alcohols the photoisomer- 
TABLE 9: Calculated Central C-C Bond Lengths $(\AA)$ of the $S_{1}$ State Adiabatic Minimum Dye Molecules in $\mathrm{C}_{6} \mathrm{H}_{6}$ and in $\mathrm{MeOH}$

\begin{tabular}{lcccc}
\hline \multirow{3}{*}{ solvent } & & \multicolumn{3}{c}{ solute } \\
\cline { 3 - 5 } & bond & I-SO & AI-SO(4) & AI-BA(4) \\
\hline $\mathrm{C}_{6} \mathrm{H}_{6}$ & $\mathrm{C}_{2}-\mathrm{C}_{3}$ & 1.400 & 1.430 & 1.431 \\
& $\mathrm{C}_{3}-\mathrm{C}_{4}$ & 1.402 & 1.403 & 1.400 \\
& $\mathrm{C}_{4}-\mathrm{C}_{5}$ & 1.408 & 1.412 & 1.419 \\
& $\mathrm{C}_{5}-\mathrm{C}_{6}$ & 1.396 & 1.401 & 1.397 \\
& $\mathrm{C}_{6}-\mathrm{C}_{7}$ & 1.405 & 1.398 & 1.415 \\
$\mathrm{MeOH}$ & $\mathrm{C}_{2}-\mathrm{C}_{3}$ & 1.393 & 1.420 & 1.422 \\
& $\mathrm{C}_{3}-\mathrm{C}_{4}$ & 1.414 & 1.416 & 1.413 \\
& $\mathrm{C}_{4}-\mathrm{C}_{5}$ & 1.395 & 1.399 & 1.410 \\
& $\mathrm{C}_{5}-\mathrm{C}_{6}$ & 1.410 & 1.414 & 1.405 \\
& $\mathrm{C}_{6}-\mathrm{C}_{7}$ & 1.397 & 1.392 & 1.414
\end{tabular}

ization rate is higher than that in nitriles with similar viscosities. ${ }^{52}$ This is partly because the hydrogen-bonding alcohols better stabilize the twisted excited state of MC 540, which has a substantial zwitterionic character leading to faster photoisomerization.

Since the explicit solute-solvent interactions vary with the solvents, and thus many factors will influence the fluorescence and lifetimes, it is not an easy task to predict or analyze the $\Phi$ values in each solvent. Here, we will analyze the geometric and electronic structures of the dye molecules in $\mathrm{C}_{6} \mathrm{H}_{6}$ and in $\mathrm{MeOH}$ to have an idea how the fluorescence quantum yield changes in general from nonpolar to polar solvents, without considering the explicit solute-solvent interactions. There is a striking difference between fluorescence quantum yields in benzene and methanol for dyes AI-SO(4), AI-BA(4), and I-SO, even though these are solvents with similar viscosities (Table 7). For I-SO, we have $\Phi\left(\mathrm{C}_{6} \mathrm{H}_{6}\right)=0.42>\Phi(\mathrm{MeOH})=0.08$. In contrast, for AI-SO(4), $\Phi\left(\mathrm{C}_{6} \mathrm{H}_{6}\right)=0.19<\Phi(\mathrm{MeOH})=0.54$. In Table 9, we present the calculated central $\mathrm{C}-\mathrm{C}$ bond lengths of the relaxed $S_{1}$ state for I-SO and AI-SO(4). The molecular orbital plots of the ground state $\left(S_{0}\right)$ HOMO and the $S_{1}$ state promoted electron are shown in Figure 8 (for I-SO) and Figure 9 (for AI-SO(4)). For I-SO, after excitation in $\mathrm{C}_{6} \mathrm{H}_{6}$, the bond lengths of $\mathrm{C}_{2}-\mathrm{C}_{3}, \mathrm{C}_{4}-\mathrm{C}_{5}$, and $\mathrm{C}_{6}-\mathrm{C}_{7}$ are lengthened (Tables 3 and 9 ), and these three bonds change from bonding to nonbonding, bonding to antibonding, and nonbonding to antibonding characters, respectively (Figure 8). Now $r\left(\mathrm{C}_{4}-\mathrm{C}_{5}\right)=1.408 \AA$ becomes the longest in the $S_{1}$ state. It is therefore very likely that the main photoisomerization coordinate is the internal rotation of $\mathrm{C}_{4}-\mathrm{C}_{5}$ for I-SO in $\mathrm{C}_{6} \mathrm{H}_{6}$ since this is the weakest bond with the greatest single bond character. In $\mathrm{MeOH}$, after excitation, the bond lengths of $\mathrm{C}_{3}-\mathrm{C}_{4}$ and $\mathrm{C}_{5}-\mathrm{C}_{6}$ are lengthened, and their bonding characters are changed from nonbonding

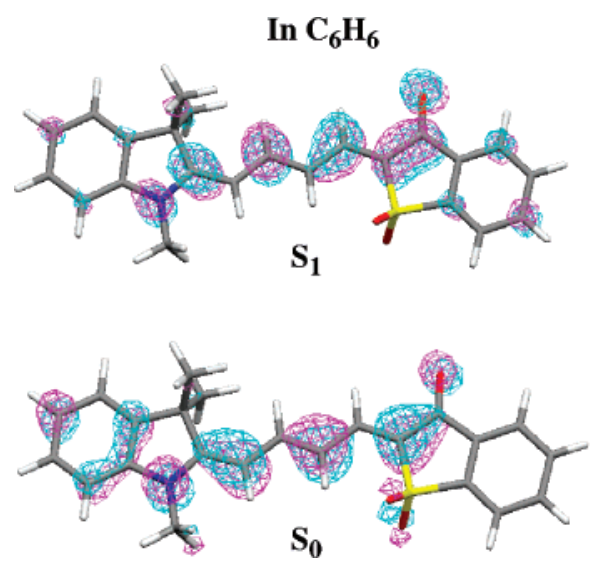

to antibonding (for $\mathrm{C}_{3}-\mathrm{C}_{4}$ ) and bonding to nonbonding (for $\left.\mathrm{C}_{5}-\mathrm{C}_{6}\right)$. Now $r\left(\mathrm{C}_{3}-\mathrm{C}_{4}\right)=1.414 \AA$, and $r\left(\mathrm{C}_{5}-\mathrm{C}_{6}\right)=1.410 \AA$. Both are longer than $r\left(\mathrm{C}_{4}-\mathrm{C}_{5}\right)$ in $\mathrm{C}_{6} \mathrm{H}_{6}$. Also, the central $\mathrm{C}-\mathrm{C}$ bonds of the $S_{1}$ state of I-SO in $\mathrm{MeOH}$ have distinct single or double bond character. By contrast, these bonds show very similar distances in $\mathrm{C}_{6} \mathrm{H}_{6}$ solution. Therefore, the internal rotations around $\mathrm{C}_{3}-\mathrm{C}_{4}$ and $\mathrm{C}_{5}-\mathrm{C}_{6}$ for the $S_{1}$ state of I-SO in $\mathrm{MeOH}$ will be easier than any bond rotations of the $S_{1}$ state of I-SO in $\mathrm{C}_{6} \mathrm{H}_{6}$. This is probably the reason that the fluorescence quantum yield of I-SO in $\mathrm{MeOH}$ is smaller than that in $\mathrm{C}_{6} \mathrm{H}_{6}$.

For the $S_{1}$ state AI-SO(4) in $\mathrm{C}_{6} \mathrm{H}_{6}, r\left(\mathrm{C}_{2}-\mathrm{C}_{3}\right)=1.430 \AA$ is obviously longer than other central $\mathrm{C}-\mathrm{C}$ bonds (Table 9 ), and its bond character changes from bonding to nonbonding upon excitation (Figure 9). For the $S_{1}$ state AI-SO(4) in $\mathrm{MeOH}$, though this bond is still the longest (1.420 ̊), it has bonding character (Figure 9) and it is shortened upon excitation (Tables 3 and 9). The other possible rotating bonds are $\mathrm{C}_{3}-\mathrm{C}_{4}$ and $\mathrm{C}_{5}-$ $\mathrm{C}_{6}$, which are lengthened after excitation, and their bonding characters change from nonbonding to antibonding (for $\mathrm{C}_{3}-$ $\mathrm{C}_{4}$ ) and bonding to nonbonding (for $\mathrm{C}_{5}-\mathrm{C}_{6}$ ). These two bond lengths $r\left(\mathrm{C}_{3}-\mathrm{C}_{4}\right)=1.416 \AA$ and $r\left(\mathrm{C}_{5}-\mathrm{C}_{6}\right)=1.414 \AA$ in $\mathrm{MeOH}$ are much shorter than $r\left(\mathrm{C}_{2}-\mathrm{C}_{3}\right)=1.430 \AA$ in $\mathrm{C}_{6} \mathrm{H}_{6}$. Therefore, the internal rotation or photoisomerization for the $S_{1}$ state AI$\mathrm{SO}(4)$ around $\mathrm{C}_{2}-\mathrm{C}_{3}$ in $\mathrm{C}_{6} \mathrm{H}_{6}$ will be easier than the rotation around $\mathrm{C}_{2}-\mathrm{C}_{3}, \mathrm{C}_{3}-\mathrm{C}_{4}$, or $\mathrm{C}_{5}-\mathrm{C}_{6}$ in $\mathrm{MeOH}$, and the fluorescence quantum yield of $\mathrm{AI}-\mathrm{SO}(4)$ in $\mathrm{C}_{6} \mathrm{H}_{6}$ is thus lower than that in $\mathrm{MeOH}$. The same reason applies for the lower fluorescence quantum yield of $\mathrm{AI}-\mathrm{BA}(4)$ in $\mathrm{C}_{6} \mathrm{H}_{6}$ relative to that in $\mathrm{MeOH}$ (Figure 6).

3.6. Photostability. The photostability of dyes is very important for applications in living cells. We have been studying the mechanism of photobleaching for merocyanines of varying structure. ${ }^{14}$ The photostability of the new dyes was characterized by exposing them to constant illumination from a halogen tungsten lamp filtered through glass. This broad spectrum light source provided essentially equal intensity throughout the spectral range where the dyes absorb and where they would be irradiated in vivo $(600-650 \mathrm{~nm})$. Bleaching occurred through intermediate formation of singlet oxygen. Photobleaching rates of the new dyes are compared in Table 10.

The bleaching rates for the dyes differed by 2 orders of magnitude. The relative rate constants $k_{\mathrm{r}}(\mathrm{rel})$ for product formation during reaction with singlet oxygen were measured by comparing the percent conversions for dyes dissolved in DMSO containing a fixed amount of ${ }^{1} \mathrm{O}_{2}(2.5 \mathrm{mM}$ solutions; ${ }^{1} \mathrm{O}_{2}$ generated by decomposition of 1,4-dimethylnaphtalene-1,4endoperoxide). The rates for dyes with a polar ground state (1a,

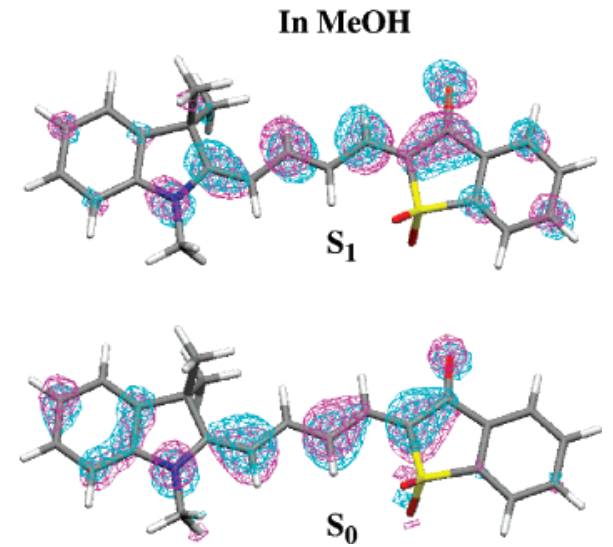

Figure 8. Molecular orbital plots for the electron in $\mathrm{HOMO}$ of the $S_{0}$ state and the $\pi \rightarrow \pi^{*}$ promoted electron in the $S_{1}$ state of I-SO in $\mathrm{C}_{6} \mathrm{H}_{6}$ and in $\mathrm{MeOH}$. 
In $\mathrm{C}_{6} \mathrm{H}_{6}$
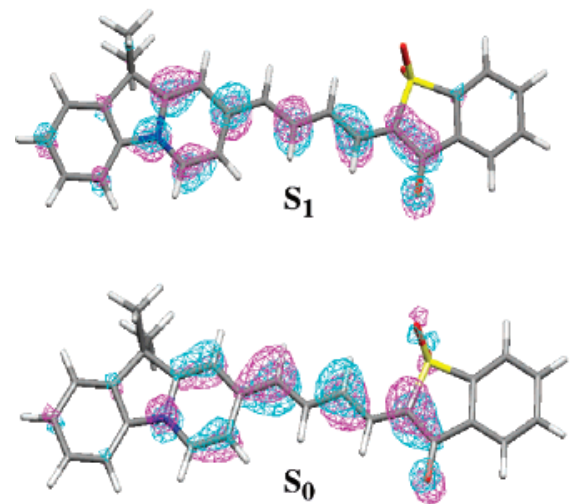

In $\mathrm{MeOH}$
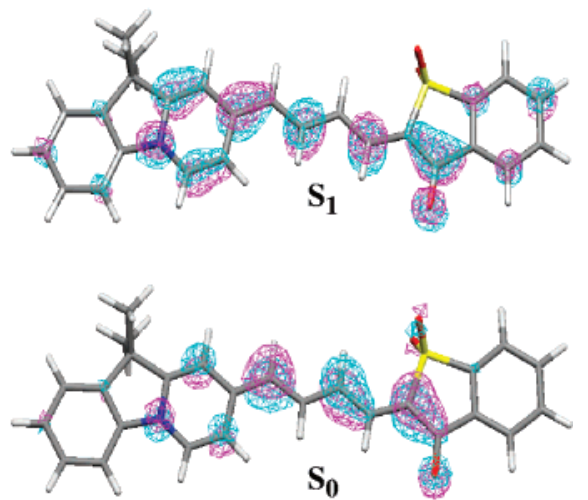

Figure 9. Molecular orbital plots for the electron in $\mathrm{HOMO}$ of the $S_{0}$ state and the $\pi \rightarrow \pi^{*}$ promoted electron in the $S_{1}$ state of $\mathrm{AI}-\mathrm{SO}(4)$ in $\mathrm{C}_{6} \mathrm{H}_{6}$ and in $\mathrm{MeOH}$.

TABLE 10: Dye Photobleaching Rates and Reactivity toward Singlet Oxygen

\begin{tabular}{|c|c|c|c|}
\hline \multirow[b]{2}{*}{ dye } & \multicolumn{2}{|c|}{$k_{\mathrm{ph}} * 10^{6}, \mathrm{~s}^{-1}\left(k_{\mathrm{ph}}(\text { rel })\right)^{a}$} & \multirow[t]{2}{*}{$k_{\mathrm{r}}(\mathrm{rel})^{b}$} \\
\hline & $\mathrm{MeOH}$ & $\mathrm{C}_{6} \mathrm{H}_{6}$ & \\
\hline $\mathbf{2 a}, \mathrm{AI}-\mathrm{SO}(4)$ & $89(261)$ & $128(115)$ & 59.2 \\
\hline 2b, AI-BA(4) & $68(200)$ & & 25.6 \\
\hline 1a, P-SO(4) & $28(82)$ & & 60.3 \\
\hline 2d, AI-SO(2) & $0.7(2.1)$ & & 20.3 \\
\hline $4, \mathrm{I}-\mathrm{SO}$ & $0.53(1.56)$ & $1.11(1.00)$ & 5.24 \\
\hline 3, I-TBA & $0.34(1.00)$ & & 1.00 \\
\hline Су5 5 & $1.89(5.56)$ & & \\
\hline
\end{tabular}

${ }^{a} k_{\mathrm{ph}}=$ absolute rate of photobleaching. $k_{\mathrm{ph}}(\mathrm{rel})=$ relative rate of photobleaching with respect to standards I-TBA in $\mathrm{MeOH}$ and I-SO in $\mathrm{C}_{6} \mathrm{H}_{6} \cdot{ }^{b} k_{\mathrm{r}}(\mathrm{rel})=$ relative rate constant for product formation during reaction of the dyes with singlet oxygen produced chemically in DMSO. All measurements were done at $25^{\circ} \mathrm{C}$.
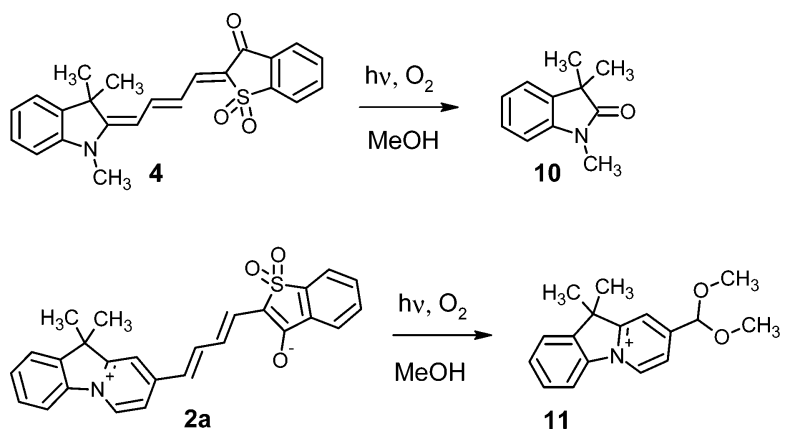

Figure 10. Products of photobleaching reactions of merocyanine dyes.

$\mathbf{2 a}, \mathbf{2 b}, \mathbf{2 d})$ were generally higher than the rates for the dyes with their ground state at the "cyanine limit" $(\mathbf{3}, \mathbf{4})$. Careful analysis of reaction mixtures revealed that the major product of dye 4 photooxidation was indol-2-one 10, while the major product of photooxidation of dye 2a was acetal $\mathbf{1 1}$ (Figure 10). The detailed analysis of these reactions and reactions products will be published elsewhere. Olefins without allylic hydrogens react with singlet oxygen to form dioxetanes. Dioxetanes are unstable and decompose to form two carbonyl compounds.

The mechanism of the reaction can be a concerted $[2+2]$ addition of singlet oxygen or it can be a polar reaction, depending on the olefin structure. Olefins with donor substituents react with singlet oxygen to form dioxetanes via zwitterionic 1,4-dipolar species. Because our dyes have donor substituents (nitrogens), it is likely that the reaction proceeds through a zwitterionic mechanism (Scheme 2). The incipient reactivity of the dyes will be determined by the extent of
TABLE 11: Calculated Atomic Electrostatic Potential Charges of the Central C Atoms of Ground-State I-SO, AI-SO(4), and AI-BA(4) in MeOH

\begin{tabular}{lcccr}
\hline \multicolumn{1}{c}{ dyes } & $\mathrm{C}_{3}$ & $\mathrm{C}_{4}$ & $\mathrm{C}_{5}$ & \multicolumn{1}{c}{$\mathrm{C}_{6}$} \\
\hline $\mathrm{I}-\mathrm{SO}$ & -0.36 & -0.10 & -0.36 & 0.02 \\
$\mathrm{AI}-\mathrm{SO}(4)$ & -0.40 & -0.11 & -0.35 & -0.02 \\
$\mathrm{AI}-\mathrm{BA}(4)$ & -0.47 & -0.09 & -0.32 & -0.04
\end{tabular}

TABLE 12: Vertical Ionization Potential $\Delta E_{\mathrm{I}}(\mathrm{eV})$ of I-SO, AI-SO(4), and AI-BA(4)

\begin{tabular}{lccc}
\hline & \multicolumn{3}{c}{ solute } \\
\cline { 2 - 4 } solvent & $\mathrm{I}-\mathrm{SO}$ & $\mathrm{AI}-\mathrm{SO}(4)$ & $\mathrm{AI}-\mathrm{BA}(4)$ \\
\hline $\mathrm{C}_{6} \mathrm{H}_{6}$ & 6.083 & 5.953 & 5.908 \\
$\mathrm{MeOH}$ & 6.296 & 6.130 & 6.234
\end{tabular}

negative charge at carbon atom $\mathrm{C}_{3}$, which is the most negatively charged atom in the dye molecules (Table 11, also see Figure $\mathrm{S} 1$ in Supporting Information). One can think of this as a chargeinduced dipole interaction between $\mathrm{C}_{3}$ and ${ }^{1} \mathrm{O}_{2}$. Our calculation showed that this charge is higher for AI-SO(4) and AI-BA(4), which react faster with singlet oxygen.

It has been suggested that the initial interaction of ${ }^{1} \mathrm{O}_{2}$ with $\mathrm{C}=\mathrm{C}$ bonds is a single-atom, end-on interaction. ${ }^{40}$ Previous studies show that the initial stage of the reaction generally proceeds through charge transfer (substrate electron donor $\rightarrow$ ${ }^{1} \mathrm{O}_{2}$ electron acceptor). ${ }^{40}$ Therefore, the rates of reaction with ${ }^{1} \mathrm{O}_{2}$ normally increase as the ionization potential of the substrate decreases. We calculated the vertical ionization potentials $\left(\Delta E_{\mathrm{I}}\right)$ of I-SO, AI-SO(4), and AI-BA(4) and compared them in Table 12. $\Delta E_{\mathrm{I}}$ is defined as:

$$
\Delta E_{\mathrm{I}}=E^{+}-E_{0}
$$

where $E_{0}$ is the full SCRF energy calculated at the COSMOoptimized geometry of the neutral ground-state dye molecule in a certain solvent, and $E^{+}$is the VSCRF energy for the dye with a positive charge at the same geometry in the same solvent. Clearly, the calculated ionization potentials of AI-SO(4) and AI-BA(4) are lower than the corresponding value of I-SO in both $\mathrm{C}_{6} \mathrm{H}_{6}$ and $\mathrm{MeOH}$ solutions. It is therefore easier for AI$\mathrm{SO}(4)$ and $\mathrm{AI}-\mathrm{BA}(4)$ to transfer an electron to ${ }^{1} \mathrm{O}_{2}$; $\mathrm{AI}-\mathrm{SO}(4)$ and AI-BA(4) show photobleaching rates (Table 10) much higher than that of I-SO, as expected on the basis of the calculated ionization potentials. We also see that $\Delta E_{\mathrm{I}}(\mathrm{MeOH})$ $>\Delta E_{\mathrm{I}}\left(\mathrm{C}_{6} \mathrm{H}_{6}\right)$ for each of the dye molecules. This is consistent with the fact that the experimentally observed photobleaching rates of $\mathrm{AI}-\mathrm{SO}(4)$ and $\mathrm{I}-\mathrm{SO}$ are higher in $\mathrm{C}_{6} \mathrm{H}_{6}$ than those in $\mathrm{MeOH}$. 
SCHEME 2: Photooxidation of I-SO and AI-SO(4) Dyes<smiles>CN1C(=O)C(C)(C)c2ccccc21</smiles><smiles>COC(OC)c1cc[n+]2c(c1)C(C)(C)c1ccccc1-2</smiles>

\section{Conclusion}

New merocyanine dyes with an enhanced contribution of the zwitterionic ground-state resonance form have been prepared through incorporation of a six-membered ring in the electron donor portion of the molecule. Positions of the absorption and emission bands for the new dyes strongly depend on solvent polarity. Their photophysical properties were correctly predicted using the SCRF/VSCRF method plus COSMO solvation model. We found that explicit $\mathrm{H}$-bonding solvent interactions were important to include in calculations to predict the correct order of the excitation and emission energies. In contrast to MC540, the new dyes show large fluorescence quantum yields in polar hydrogen-bonding solvents. This can be explained by the DFT results that charge transfer upon excitation produces an excited state with a low contribution from the zwitterionic form. The nonpolar excited state is less susceptible to hydrogen-bond formation with solvent and consequent nonradiative activation through photoisomerization.

Since the positions of singlet oxygen attack in the dye molecules are predicted (atom $\mathrm{C}_{3}$ ), efforts are being made to improve the photostability of these dyes by attaching an electronaccepting group to atom $\mathrm{C}_{3}$ to inhibit the charge transfer from $\mathrm{C}_{3}$ to ${ }^{1} \mathrm{O}_{2}$. The cyano group $(-\mathrm{C} \equiv \mathrm{N})$ has been chosen for this purpose and attached to I-SO and S-SO.$^{53}$ This greatly improved the photostability of the dyes. ${ }^{53}$ Efforts to improve the photostability of other solvent-sensitive dyes are ongoing. On the other hand, photobleaching of the new dyes can be useful in making powerful phototoxins. It is well known that certain cyanine dyes, such as MC540, are selectively assimilated into leukemia cells, even in the presence of a large excess of healthy cells. ${ }^{49,51,54-56}$ They can be used to detect labeled cells, and then function as potent phototoxins toward the host cells after photobleaching. MC540, however, suffers from its very modest quantum yields of both triplet formation and singlet molecular oxygen generation. There is scope for an increase in cytotoxicity by improving the photophysical properties without significantly changing molecular properties such as selectivity and cellular and tissue localization. ${ }^{57}$

Acknowledgment. A.T. and W.-G.H. contributed equally to this work. Financial support from the NIH (Grants GM057464 and GM064346 for K.H. and GM43278 for L.N.), Novartis, and Panomics, Inc. is gratefully acknowledged. The support of computer resources of The Scripps Research Institute is also acknowledged.

Supporting Information Available: The Cartesian coordinates of the $S_{0}$ and $S_{1}$ states COSMO-optimized dye structures and more detailed atomic electrostatic potential charges of the $S_{0}$ state dye molecules in $\mathrm{MeOH}$. This material is available free of charge via the Internet at http://pubs.acs.org.

\section{References and Notes} 172.

(1) Hahn, K.; Toutchkine, A. Curr. Opin. Cell Biol. 2002, 14, 167-

(2) Kraynov, V. S.; Chamberlain, C.; Bokoch, G. M.; Schwartz, M. A.; Slabaugh, S.; Hahn, K. M. Science 2000, 290, 333-337.

(3) Chamberlain, C.; Hahn, K. M. Traffic 2000, 1, 755-762. 

738

(4) Hahn, K.; Debiasio, R.; Taylor, D. L. Nature 1992, 359, 736-

(5) Giuliano, K. A.; Taylor, D. L. Trends Biotechnol. 1998, 16, 135140.

6) Cerione, R. A. Methods Enzymol. 1994, 237, 409-423.

(7) Nomanbhoy, T. K.; Cerione, R. A. J. Biol. Chem. 1996, 271, $10004-10009$

(8) Nomanbhoy, T.; Cerione, R. A. Biochemistry 1999, 38, 1587815884

(9) Baburaj, K.; Azam, N.; Udgaonkar, D.; Durani, S. Biochim. Biophys. Acta 1994, 1199, 253-265.

(10) Prendergast, F. G.; Meyer, M.; Carlson, G. L.; Iida, S.; Potter, J. D. J. Biol. Chem. 1983, 258, 7541-7544.

(11) Rasmussen, S. G. F.; Carroll, F. I.; Maresch, M. J.; Jensen, A. D.; Tate, C. G.; Gether, U. J. Biol. Chem. 2001, 276, 4717-4723.

(12) Morii, T.; Sugimoto, K.; Makino, K.; Otsuka, M.; Imoto, K.; Mori, Y. J. Am. Chem. Soc. 2002, 124, 1138-1139.

(13) Daugherty, D. L.; Gellman, S. H. J. Am. Chem. Soc. 1999, 121, 4325-4333.

(14) Toutchkine, A.; Kraynov, V.; Hahn, K. J. Am. Chem. Soc. 2003 , $125,4132-4145$

(15) Nalbant, P.; Hodgson, L.; Kraynov, V.; Toutchkine, A.; Hahn, K. M. Science 2004, 305, 1615-1619.

(16) Bourhill, G.; Bredas, J. L.; Cheng, L. T.; Marder, S. R.; Meyers, F.; Perry, J. W.; Tiemann, B. G. J. Am. Chem. Soc. 1994, 116, 26192620 .

(17) Gorman, C. B.; Marder, S. R. Chem. Mater. 1995, 7, 215-220

(18) Bublitz, G. U.; Ortiz, R.; Marder, S. R.; Boxer, S. G. J. Am. Chem. Soc. 1997, 119, 3365-3376.

(19) Liu, T.; Han, W.-G.; Himo, F.; Ullmann, G. M.; Bashford, D.; Toutchkine, A.; Hahn, K. M.; Noodleman, L. J. Phys. Chem. A 2004, 108 , $3545-3555$.

(20) Han, W.-G.; Liu, T.; Himo, F.; Toutchkine, A.; Bashford, D.; Hahn, K. M.; Noodleman, L. ChemPhysChem 2003, 4, 1084-1094.

(21) Klamt, A.; Schüürmann, G. J. Chem. Soc., Perkin Trans. 2 1993, 799-805.

(22) Klamt, A. J. Phys. Chem. 1995, 99, 2224-2235.

(23) Klamt, A.; Jonas, V. J. Chem. Phys. 1996, 105, 9972-9981.

(24) Pye, C. C.; Ziegler, T. Theor. Chem. Acc. 1999, 101, 396-408.

(25) ADF 2000.02; SCM, Vrije Universiteit: Amsterdam, The Netherlands. http://www.scm.com.

(26) Vosko, S. H.; Wilk, L.; Nusair, M. Can. J. Phys. 1980, 58, 12001211.

(27) Becke, A. D. Phys. Rev. A 1988, 38, 3098-3100.

(28) Perdew, J. P. Phys. Rev. B 1986, 33, 8822-8824.

(29) Perdew, J. P. Phys. Rev. B 1986, 34, 7406-7406.

(30) Hahn, K. M.; Waggoner, A. S.; Taylor, D. L. J. Biol. Chem. 1990, 265, 20335-20345.
(32) Jones, G.; Jackson, W. R.; Choi, C.; Bergmark, W. R. J. Phys. Chem. 1985, 89, 294-300.

(33) Gustavsson, T.; Cassara, L.; Gulbinas, V.; Gurzadyan, G.; Mialocq, J. C.; Pommeret, S.; Sorgius, M.; van der Meulen, P. J. Phys. Chem. A 1998, 102, 4229-4245.

(34) Mccarthy, P. K.; Blanchard, G. J. J. Phys. Chem. 1993, 97, 1220512209

(35) Davis, M. M.; Hetzer, H. B. Anal. Chem. 1966, 38, 451-461.

(36) Sackett, D. L.; Wolff, J. Anal. Biochem. 1987, 167, 228-234.

(37) Chen, J. L.; Noodleman, L.; Case, D. A.; Bashford, D. J. Phys. Chem. 1994, 98, 11059-11068.

(38) Bashford, D. An Object-Oriented Programming Suite for Electrostatic Effects in Biological Molecules. In Scientific Computing in ObjectOriented Parallel Environments; Ishikawa, Y., Oldehoeft, R. R., Reynders, J. V. W., Tholburn, M., Eds.; Lecture Notes in Computer Science 1343; Springer: Berlin, 1997; pp 233-240.

(39) Li, J.; Nelson, M. R.; Peng, C. Y.; Bashford, D.; Noodleman, L. J. Phys. Chem. A 1998, 102, 6311-6324.

(40) Turro, N. J. Modern Molecular Photochemistry; University Science Books: Mill Valley, CA, 1991

(41) Mennucci, B.; Cammi, R.; Tomasi, J. J. Chem. Phys. 1998, 109, 2798-2807.

(42) Mennucci, B. J. Am. Chem. Soc. 2002, 124, 1506-1515.

(43) Cossi, M.; Barone, V. J. Chem. Phys. 2000, 112, 2427-2435.

(44) Cossi, M.; Barone, V. J. Chem. Phys. 2001, 115, 4708-4717.

(45) Cossi, M.; Rega, N.; Scalmani, G.; Barone, V. J. Chem. Phys. 2001 $114,5691-5701$

(46) Barone, V.; Palma, A.; Sanna, N. Chem. Phys. Lett. 2003, 381, $451-457$.

(47) Baba, H.; Goodman, L.; Valenti, P. C. J. Am. Chem. Soc. 1966, $88,5410-5415$

(48) Valeur, B. Molecular Fluorescence: Principles and Applications;

Wiley-VCH: Weinheim, Germany, 2002.

(49) Benniston, A. C.; Harriman, A.; McAvoy, C. J. Chem. Soc. Faraday Trans. 1997, 93, 3653-3662.

(50) Benniston, A. C.; Harriman, A. J. Chem. Soc., Faraday Trans. 1994 $90,2627-2634$

(51) Benniston, A. C.; Harriman, A. J. Chem. Soc., Faraday Trans. 1998, 94, $1841-1847$

(52) Onganer, Y.; Yin, M.; Bessire, D. R.; Quitevis, E. L. J. Phys. Chem. 1993, 97, 2344-2354.

(53) Toutchkine, A.; Nguyen, D.-V.; Hahn, K. M. Org. Lett. 2007, 9, $2775-2777$.

(54) Singh, R. J.; Feix, J. B.; Kalyanaraman, B. Photochem. Photobiol. 1992, 55, 483-489.

(55) Franck, B.; Schneider, U. Photochem. Photobiol. 1992, 56, 271276.

(56) Sieber, F. Photochem. Photobiol. 1987, 46, 1035-1042.

(57) Redmond, R. W.; Srichai, M. B.; Bilitz, J. M.; Schlomer, D. D.; Krieg, M. Photochem. Photobiol. 1994, 60, 348-355. 